\title{
Modelling turbulent vertical mixing sensitivity using a 1-D version of NEMO
}

\author{
G. Reffray ${ }^{1}$, R. Bourdalle-Badie ${ }^{1}$, and C. Calone ${ }^{2}$ \\ ${ }^{1}$ Mercator Océan, Toulouse, France \\ ${ }^{2}$ LGGE, Grenoble, France \\ Correspondence to: G. Reffray (greffray@ mercator-ocean.fr)
}

Received: 2 July 2014 - Published in Geosci. Model Dev. Discuss.: 8 August 2014

Revised: 21 November 2014 - Accepted: 16 December 2014 - Published: 22 January 2015

\begin{abstract}
Through two numerical experiments, a 1-D vertical model called NEMO1D was used to investigate physical and numerical turbulent-mixing behaviour. The results show that all the turbulent closures tested $(k+l$ from Blanke and Delecluse, 1993, and two equation models: generic length scale closures from Umlauf and Burchard, 2003) are able to correctly reproduce the classical test of Kato and Phillips (1969) under favourable numerical conditions while some solutions may diverge depending on the degradation of the spatial and time discretization. The performances of turbulence models were then compared with data measured over a 1-year period (mid-2010 to mid-2011) at the PAPA station, located in the North Pacific Ocean. The modelled temperature and salinity were in good agreement with the observations, with a maximum temperature error between -2 and $2{ }^{\circ} \mathrm{C}$ during the stratified period (June to October). However, the results also depend on the numerical conditions. The vertical RMSE varied, for different turbulent closures, from 0.1 to $0.3^{\circ} \mathrm{C}$ during the stratified period and from 0.03 to $0.15^{\circ} \mathrm{C}$ during the homogeneous period. This 1-D configuration at the PAPA station (called PAPA1D) is now available in NEMO as a reference configuration including the input files and atmospheric forcing set described in this paper. Thus, all the results described can be recovered by downloading and launching PAPA1D. The configuration is described on the NEMO site (http://www.nemo-ocean.eu/Using-NEMO/ Configurations/C1D_PAPA). This package is a good starting point for further investigation of vertical processes.
\end{abstract}

\section{Introduction}

Copernicus is a multidisciplinary programme of the European Union for sustainable services providing information on monitoring of the atmosphere, climate change, and land and marine environments. The services also address the management of emergency and security-related situations (http: //www.copernicus.eu/). The GMES (Global Monitoring for Environment and Security) marine service was the precursor of Copernicus and has ensured the systematic monitoring and forecasting of the state of oceans at regional and global scales. Within the GMES/MyOcean project, Mercator Océan, one of the French operational oceanography teams, has implemented an operational, global, eddy-resolving system at $1 / 12^{\circ}$ and a regional system at $1 / 36^{\circ}$ covering the French and Iberian Peninsula coasts. The NEMO (Nucleus for European Modelling of the Ocean; Madec, 2008) ocean model has been used for both systems.

NEMO is a numerical-modelling tool developed and operated within a European consortium. Its code enables investigation of oceanic circulation (OPA) and its interactions with the atmosphere. Ice models (LIM) and biogeochemical models (TOP - PISCES or LOBSTER) could also be coupled. This primitive equation model offers a wide range of applications from short-term forecasts (Mercator Océan and MyOcean/Copernicus) and climate projections (Voldoire et al., 2013) to process studies (e.g. Chanut et al., 2008; Bernie et al., 2007).

OPA, the oceanic component of NEMO, is built from the Navier-Stokes equations applied to the earth referential system, in which the ocean is subjected to the Coriolis force. The prognostic variables are the horizontal components of veloc- 
ity, the sea surface height and two active tracers (temperature and salinity).

These equations allow description of a wide range of processes at any spatial and temporal scales. This involves interpreting complex numerical results, which means that it is difficult to improve the model due to the multiple non-linear interactions between the different equation terms. Fortunately, there are a lot of numerical test cases in the literature that make it possible to isolate each term of the equations (advection, diffusion or coordinate systems) and improve it independently of the others.

Vertical mixing plays an essential role in ocean dynamics and it must therefore be correctly estimated. In particular, it creates the mixed layer, the homogeneous ocean layer that interacts directly with the atmosphere, which can then be modelled as the mixed layer depth (MLD). The MLD plays a very important role in the energetic exchanges between the ocean and the atmosphere and may have very high spatiotemporal variations (diurnal, seasonal, synoptical). In addition, MLD variability plays a crucial role in biogeochemical processes. The deepening episodes of the MLD during winter inject nutrients into the euphotic layer, with a strong impact on primary production (Flierl and Davis, 1993). Vertical mixing is also responsible for convection or seasonal stratification. Lastly, vertical mixing must be able to conserve the water masses.

To focus on vertical turbulent mixing, we use NEMO1D, a feature included in NEMO, to consider only one column of water. NEMO1D is a simple, robust, useful and powerful tool that enables quick and easy investigation of the physical processes affecting the vertical component of the ocean state variables: turbulence, surface and bottom boundary conditions, penetration radiation schemes, etc.

In this paper, based on the 1-D configuration, we assess the effectiveness of different turbulent schemes available in NEMO. Section 2 describes the equations of motions, the turbulent closures discussed in this paper and the numerical contexts (vertical grids and time steps). Section 3.1 contains a discussion of how the turbulence models performed in relation to the empirical law which states that the mixed layer deepens as a function of time, as described by Kato and Phillips 1969) and based on a laboratory experiment. The sensitivity of the spatial and time discretization of each turbulent scheme is also discussed. Section 3.2 reports on some experiments performed under realistic conditions and these turbulent closures are compared with data measurements taken at the PAPA station (http://www.pmel.noaa.gov/OCS/Papa/ index-Papa.shtml). This buoy, located in a region of weak horizontal advection, is commonly used by the community to validate turbulent closures (Burchard and Bolding, 2001). The last section contains the conclusion and perspectives for future investigation.

\section{Model description}

\subsection{Equations of motions}

NEMO is based on the 3-D primitive equations resulting from Reynolds averaging of the Navier-Stokes equations and transport equations for temperature and salinity. The set of equations is:

$$
\begin{aligned}
& \frac{\partial u_{i}}{\partial t}+u_{j} \frac{\partial\left(u_{i}\right)}{\partial x_{j}}=-\frac{1}{\rho_{0}} \frac{\partial P}{\partial x_{i}} \\
& \quad-\frac{\partial}{\partial x j}\left(\overline{u_{j}^{\prime} u_{i}^{\prime}}-v_{\mathrm{mol}} \frac{\partial u_{i}}{\partial x j}\right)+f_{i} \\
& \frac{\partial T}{\partial t}+u_{j} \frac{\partial(T)}{\partial x_{j}}=-\frac{\partial}{\partial x j}\left(\overline{u_{j}^{\prime} T^{\prime}}-K_{\mathrm{mol}} \frac{\partial T}{\partial x j}\right) \\
& \quad+\frac{1}{\rho_{0} C_{\mathrm{p}}} \frac{\partial I\left(F_{\mathrm{sol}}, z\right)}{\partial z} \\
& \frac{\partial S}{\partial t}+u_{j} \frac{\partial(S)}{\partial x_{j}}=-\frac{\partial}{\partial x j}\left(\overline{u_{j}^{\prime} S^{\prime}}-K_{\mathrm{mol}} \frac{\partial S}{\partial x j}\right) \\
& \quad+E_{\mathrm{f}}-P_{\mathrm{f}},
\end{aligned}
$$

where $u_{i\{i=1,2\}}$ represents the horizontal components of the velocity, $T$ the temperature, $S$ the salinity, $x_{j\{i=1,3\}}=$ $(x, y, z)$ are the horizontal and vertical directions, $t$ the temporal dimension, $f_{i\{i=1,2\}}$ the components of the Coriolis term, $P$ the pressure, $I$ the downward irradiance, $F_{\text {sol }}$ the penetrative part of the surface heat flux, $\rho_{0}$ the reference density and $C_{\mathrm{p}}$ the specific heat capacity. $E_{\mathrm{f}}$ and $P_{\mathrm{f}}$ are respectively the evaporation and precipitation fluxes while $v_{\mathrm{mol}}$ and $K_{\mathrm{mol}}$ are respectively the molecular viscosity and molecular diffusivity.

${\overline{u_{j}^{\prime}}}_{i}^{\prime}$ are the Reynolds stresses, $\overline{u_{j}^{\prime} T^{\prime}}$ and $\overline{u_{j}^{\prime} S^{\prime}}$ are the turbulent scalar fluxes. After a scaling analysis, only the vertical terms are kept and are parameterized as:

$\overline{u_{i}^{\prime} w^{\prime}}=-v_{\mathrm{t}} \frac{\partial u_{i}}{\partial z}$
$\overline{T^{\prime} w^{\prime}}=-K_{\mathrm{t}} \frac{\partial T}{\partial z}$
$\overline{S^{\prime} w^{\prime}}=-K_{\mathrm{t}} \frac{\partial S}{\partial z}$,

where $v_{\mathrm{t}}$ and $K_{\mathrm{t}}$ are respectively the vertical turbulent viscosity and diffusivity.

\subsection{Vertical turbulence models}

The turbulence issue raises the question of how to compute accurately the vertical turbulent viscosity $v_{\mathrm{t}}$ and diffusivity $K_{\mathrm{t}}$. in Eq. (2a)-(2c). There are many ways of computing these turbulent coefficients. The simplest method involves replacing them by constant values or parameterizing them as a function of the Richardson number $R i$, defined as the ratio of 
the buoyancy to the shear:

$$
\begin{aligned}
v_{\mathrm{t}} & =\frac{v_{\mathrm{t} 0}}{(1+a R i)^{b}} \\
K_{\mathrm{t}} & =\frac{K_{\mathrm{t} 0}}{\left(1+a^{\prime} R i\right)^{b^{\prime}}} \\
R i & =\frac{N^{2}}{M^{2}} \text { with } N^{2}=-\frac{g}{\rho_{0}} \frac{\partial \rho}{\partial z} \\
& \text { and } M^{2}=\sum_{i=1}^{2}\left(\frac{\partial u_{i}}{\partial z}\right)^{2},
\end{aligned}
$$

where $N^{2}$ is the Brunt-Väisälä frequency, $\rho$ the density and $g=9.81 \mathrm{~m} \mathrm{~s}^{-2}$ the gravitational acceleration. $v_{\mathrm{t} 0}$ and $K_{\mathrm{t} 0}$ correspond to background values and $a, b, a^{\prime}$ and $b^{\prime}$ are constants depending on the selected closure (Munk and Anderson, 1948; Paconowski and Philander, 1981).

Other more complex methods use the turbulent kinetic energy $k$ and the mixing length $l$ to estimate the turbulent coefficients. Then, in these cases $v_{\mathrm{t}}$ and $K_{\mathrm{t}}$ are expressed as:

$v_{\mathrm{t}}=C_{\mu} \sqrt{k} l$

$K_{\mathrm{t}}=C_{\mu}^{\prime} \sqrt{k} l$,

where $C_{\mu}$ and $C_{\mu}^{\prime}$ can represent stability functions or constants. The problem becomes to determine the values of $k$, $l, C_{\mu}$ and $C_{\mu}^{\prime} . k$ is usually computed with a differential equation. $l$ can be parameterized using an algebraic relation (one-equation model) or computed using a second differential equation (two-equation model).

The main objective of the present paper is to highlight and to understand the performance of a two-equation model compared to the standard turbulent model of NEMO referred to as the one-equation model. Simpler models than those described in Eq. (3a)-(3c) or other kinds of models such as such as K-Profile Parameterization (commonly called KPP suggested by Large et al., 1994) are not considered here, and could be considered in a further study.

The different ways of estimating $k, l, C_{\mu}$ and $C_{\mu}^{\prime}$ are described in the following sections. The surface boundary conditions are also described and discussed.

\subsubsection{Turbulent kinetic energy}

For the one-equation as for the two-equation model, the turbulent kinetic energy $(k)$ is computed according to the following transport equation:

$$
\frac{\partial k}{\partial t}=D_{k}+P+G-\varepsilon,
$$

where $D_{k}$ represents the turbulent and viscous transport terms expressed as:

$$
D_{k}=\frac{\partial}{\partial z} \frac{v_{\mathrm{t}}}{\sigma_{k}} \frac{\partial k}{\partial z}
$$

with $\sigma_{k}$ a constant Schmidt-number.

$P$ and $G$ in Eq. (5) relate to the production of turbulent kinetic energy respectively by shear and buoyancy:

$$
\begin{aligned}
& P=v_{\mathrm{t}} M^{2} \\
& G=K_{\mathrm{t}} N^{2} .
\end{aligned}
$$

However, $G$ is a term for production of turbulent kinetic energy only in unstable situations. In stable situations, this term reflects the destruction of the turbulence due to stratification.

Finally, $\varepsilon$ in Eq. (5) is the rate of dissipation:

$$
\varepsilon=\left(C_{\mu}^{0}\right)^{3} \frac{k^{3 / 2}}{l},
$$

where $C_{\mu}^{0}$ denotes a constant of the model.

\subsubsection{The mixing length}

The mixing length $l$ can be either parameterized using an algebraic formulation (Blanke and Delecluse, 1993 or Xing and Davies, 1999) or computed using a second prognostic differential equation (Umlauf and Burchard, 2003). These types of closure are respectively referred to as one- and twoequation models (Burchard et al., 2008).

The turbulent model, most frequently used by the NEMO community and commonly called the TKE model, is a oneequation model suggested by Blanke and Delecluse (1993). The parameterization of the mixing length is a simplification of the formulation of Gaspar et al. (1990) by considering only one mixing length established under the assumption of a linear stratified fluid. This mixing length is then simply computed as a ratio between the turbulent velocity fluctuations and the Brunt-Väisälä frequency:

$l=\frac{(2 k)^{1 / 2}}{N}$.

In addition, this mixing length is bounded by the distances between the calculation point position and the physical boundaries (surface and bottom).

The two-equation models, most frequently used by the ocean modelling community, are: $k-k l$ (Mellor and Yamada, 1982), $k-\varepsilon$ (Rodi, 1987) and $k-\omega$ (Wilcox, 1988). According to Umlauf and Burchard (2003), the turbulent quantities $k l, \varepsilon$ and $\omega$ can be expressed using a generic length scale (GLS):

$\Psi=\left(C_{\mu}^{0}\right)^{p} k^{m} l^{n}$,

where $p, m$ and $n$ are real numbers (see Table 1).

The transport equation for the variable $\Psi$ can be formulated as:

$\frac{\partial \psi}{\partial t}=D_{\psi}+\frac{\psi}{k}\left(C_{\psi 1} P+C_{\psi 3} G-C_{\psi 2} \varepsilon\right)$, 
Table 1. Turbulence model constants.

\begin{tabular}{lrllll}
\hline Constants & TKE & $k-k l$ & $k-\varepsilon$ & $k-\omega$ & Generic \\
\hline$p$ & - & 0 & 3 & -1 & 0 \\
$m$ & - & 1 & 1.5 & 0.5 & 1 \\
$n$ & - & 1 & -1 & -1 & -0.67 \\
$C_{\mu}$ & 0.1 & Canuto A & Canuto A & Canuto A & Canuto A \\
$C_{\mu}^{\prime}$ & $0.1 / P r$ & Canuto A & Canuto A & Canuto A & Canuto A \\
$\left(C_{\mu}^{0}\right)^{3}$ & 0.7 & $(0.5268)^{3}$ & $(0.5268)^{3}$ & $(0.5268)^{3}$ & $(0.5268)^{3}$ \\
$C_{\Psi 1}$ & - & 0.9 & 1.44 & 0.555 & 1 \\
$C_{\Psi 2}$ & - & $0.5 F_{\text {wall }}$ & 1.92 & 0.833 & 1.22 \\
$C_{\Psi 3}$ (stable) & - & 2.62 & -0.629 & -0.64 & 0.05 \\
$C_{\Psi 3}$ (unstable) & - & 1 & 1 & 1 & 1 \\
$\sigma_{\kappa}$ & 1 & 1.96 & 1 & 2 & 0.8 \\
$\sigma_{\Psi}$ & - & 1.96 & 1.2 & 2 & 1.07 \\
\hline
\end{tabular}

where $C_{\Psi 1}, C_{\Psi 2}$ and $C_{\Psi 3}$ are constants to be defined and $D_{\Psi}$ represents the turbulent and viscous terms of $\Psi$ expressed as:

$D_{\psi}=\frac{\partial}{\partial z} \frac{v_{\mathrm{t}}}{\sigma_{\psi}} \frac{\partial \Psi}{\partial z}$,

where $\sigma_{\Psi}$ is a constant Schmidt-number.

\subsubsection{Stability functions}

The stability functions appear in Eq. (4a) and (4b).

For the TKE model, they are:

$C_{\mu}=0.1$

$C_{\mu}^{\prime}=0.1 / P r$,

with $P r$, the Prandtl number, defined as a function of the Richardson number:

$\left\{\begin{array}{l}P r=5 R i \text { if } R i \geq R i_{c} \\ P r=1 \text { otherwise }\end{array}\right.$,

where $R i_{\mathrm{c}}=0.2$ is the critical Richardson number.

For GLS models, the stability functions are derived from the Reynolds stress equations and depend on the shear and buoyancy numbers, defined in Eq. (3c), called respectively $\alpha_{M}$ and $\alpha_{N}$ and expressed as:

$\alpha_{M}=\frac{k^{2}}{\varepsilon^{2}} M^{2}$ and $\alpha_{N}=\frac{k^{2}}{\varepsilon^{2}} N^{2}$.

There are several articles on stability functions in the literature. The main functions commonly used by the research community are Galperin et al. (1988), Kantha and Clayson (1994), Hossain (1980) and Canuto A and B (Canuto et al., 2001). This study does not discuss any sensitivity tests for these functions. This has in fact been done by Burchard and Bolding (2001), who claim that better results are obtained with the Canuto A stability functions. Thus, they were naturally chosen for the study presented in this paper and are expressed as:

$C_{\mu}=$

$\frac{0.731+0.119 \alpha_{N}-0.00082 \alpha_{M}}{1+0.2555 \alpha_{N}+0.02872 \alpha_{M}+0.008677 \alpha_{N}^{2}+0.005222 \alpha_{M} \alpha_{N}-0.0000337 \alpha_{M}^{2}}$

$C_{\mu}^{\prime}=$

$\frac{0.766+0.0309 \alpha_{N}+0.00602 \alpha_{M}}{1+0.2555 \alpha_{N}+0.02872 \alpha_{M}+0.008677 \alpha_{N}^{2}+0.005222 \alpha_{M} \alpha_{N}-0.0000337 \alpha_{M}^{2}}$

$\operatorname{Pr}$ is then determined as:

$\operatorname{Pr}=v_{\mathrm{t}} / K_{\mathrm{t}}=C_{\mu} C_{\mu}^{\prime}$.

For information, the $R i_{\mathrm{c}}$ for the stability functions of Canuto A is 0.847 .

\subsubsection{Surface boundary condition}

The ocean surface is subjected to atmospheric forcing and eventually surface wave breaking that could induce significant mixing.

\section{Logarithmic boundary layer}

In the absence of an explicit wave description, the surface turbulent quantities can be described as a logarithmic boundary layer with the following properties:

$k=\lambda u_{*}^{2}$ if $P=\varepsilon$

$l=\kappa\left(z+z_{0}\right)$

$D_{k}=-\frac{v_{\mathrm{t}}}{\sigma_{k}} \frac{\partial k}{\partial z}=0$,

where $z$ is the distance from the sea surface, $z_{0}$ is the surface roughness, $u_{*}$ is the friction velocity and $\lambda$ is a constant depending on the turbulence closure.

Inside this logarithmic boundary layer, the turbulent kinetic energy is constant and its flux is zero. The stability functions of Canuto A used in the GLS closures (Eq. 16a 
and 16b) converge to the value $C_{\mu}^{0}$. The constants $\lambda$ depend on the turbulence model and can be expressed as:

$\lambda=\frac{1}{\sqrt{C_{\mu}\left(C_{\mu}^{0}\right)^{3}}}=\frac{1}{\sqrt{0.1 \cdot 0.7}}=3.75$

for TKE closures and

$\lambda=\frac{1}{\left(C_{\mu}^{0}\right)^{2}}=\frac{1}{(0.5268)^{2}}=3.6$

for GLS closures using Canuto A .

Both of these values are closed to the typical value of $\frac{10}{3}$ given by Townsend (1976) for a logarithmic boundary layer.

\section{Mixing induced by breaking waves}

Breaking waves induce significant mixing inside the surface layer through the diffusion term, as proposed by Craig and Banner (1994):

$D_{k}=-\frac{v_{\mathrm{t}}}{\sigma_{k}} \frac{\partial k}{\partial z}=C_{\mathrm{w}} u_{*}^{3}\left(\frac{z+z_{0}}{z_{0}}\right)^{3 \alpha / 2}$,

where $C_{\mathrm{w}}$ is an empirical parameter depending on the wave age, and usually estimated to be $C_{\mathrm{w}}=100$ for a fully developed wave or $C_{\mathrm{w}}=0$ if no surface wave breaking is considered to again fall within Eq. (18c).

For the TKE model, the simplification of Eq. (21) leads to a value of turbulent kinetic energy at the surface $(z=0)$ similar to that of Eq. (18a) as proposed by Mellor and Blumberg (2004):

$k=\frac{1}{2}\left(15.8 C_{W}\right)^{\frac{2}{3}} u_{*}^{2}$

$l=\kappa z_{0}$.

In addition, to enable the mixing induced by breaking waves to penetrate the water column, a percentage of the surface turbulent kinetic energy is injected below the surface. The total turbulent kinetic energy is then determined as follows:

$k_{\mathrm{tot}}(z)=k_{\mathrm{eq}}(z)+\alpha_{\mathrm{bc}} k_{\mathrm{bc}}(z=0) e^{-\frac{z}{H_{\mathrm{p}}}}$ for $z \neq 0$,

where $k_{\mathrm{eq}}$ is the turbulent kinetic energy computed with Eq. (5), $k_{\mathrm{bc}}$ is the surface turbulent kinetic energy computed with Eq. (22a), $\alpha_{\mathrm{bc}}$ is a percentage set to $5 \%$ and $H_{\mathrm{p}}$ is the depth of penetration. In most cases, $H_{\mathrm{p}}$ varies as a function of the latitude $(0.5 \mathrm{~m}$ at the equator to a maximum of $30 \mathrm{~m}$ at the middle latitudes).

In the GLS model, if the surface breaking waves mixing is considered, then shear-free turbulence may be assumed. This special case is characterized by a spatial decay of turbulence away from a source without mean shear. In these conditions, the turbulence solution can be written as:

$$
\begin{aligned}
& k=K\left(z+z_{0}\right)^{\alpha} \\
& l=L\left(z+z_{0}\right) \\
& D_{k}=\varepsilon,
\end{aligned}
$$

where $\alpha$ is the decay exponent for the turbulent kinetic energy expressed as:

$\alpha=-\frac{4 n\left(\sigma_{k}\right)^{1 / 2}}{(1+4 m)\left(\sigma_{k}\right)^{1 / 2}-\left(\sigma_{k}+24 \sigma_{k} C_{\psi 2}\right)^{1 / 2}}$

and $L$ is a constant of proportionality for the length scale expressed as:

$$
L=C_{\mu}^{0}\left(\frac{C_{\mu}^{0}}{C_{\mu}^{\mathrm{sf}}}\right)^{1 / 2}
$$

$\left(\frac{\left(1+4 m+8 m^{2}\right) \sigma_{k}+12 \sigma_{\Psi} C_{\psi 2}-(1+4 m)\left(\sigma_{k}\left(\sigma_{k}+24 \sigma_{\Psi} C_{\psi 2}\right)\right)^{1 / 2}}{12 n^{2}}\right)^{\frac{1}{2}}$

where $C_{\mu}^{\mathrm{sf}}$ is the shear free value of the stability function, estimated to 0.731 for the Canuto A (Eq. 16a with $\alpha_{M}=\alpha_{N}=0$ ). This value is slightly higher than the value of $C_{\mu}^{0}=0.5268$ established inside the logarithmic boundary layer (Eq. 20).

Note that the value of $\alpha$ in Eq. (25) must be between -2 and -3 , and the value of $L$ in Eq. (26) must be slightly smaller than the von Karman constant $\kappa=0.41$. The values of $\alpha$ and $L$ computed with the $k-\varepsilon$ are not correct when the absolute value of $\alpha$ is too high or the value for $L$ too low (Burchard, 2001b). To overcome this failure, the relation (25) is used to compute the optimal $\sigma_{k}$ obtained with $\alpha=-1.5$. A transition function is then necessary for $\sigma_{k}$ to tend towards this surface value.

\section{Surface roughness}

For the TKE model, the surface roughness is computed using Charnock's relation (1955):

$z_{0}=\frac{\beta}{g} u_{*}^{2}$,

where $\beta=2 \times 10^{5}$ is an empirical constant (Stacey, 1999).

For GLS models, $z_{0}$ is expressed as a function of the significant wave height $H_{\mathrm{s}}$ expressed as a function of the wave age $W_{\text {age }}$ as suggested by Rascle et al. (2008):

$$
\begin{gathered}
z_{0}=1.3 \mathrm{H}_{\mathrm{s}}=1.3 \frac{665}{0.85 g} u_{*}^{2} W_{\mathrm{age}}^{\frac{3}{2}} \\
\text { with } W_{\text {age }}=30 \tanh \left(\frac{0.6}{28 u_{*}}\right) .
\end{gathered}
$$

For all models, a background value of the surface roughness is set to $z_{0 \_}$bg $=0.02 \mathrm{~m}$. 


\subsubsection{Model constants and calibration}

The values of constants are condensed in Table 1 and depend on the selected closure model.

For the TKE model, the constants of Eqs. (13a), (13b) and (8) are similar to that of the model of Gaspar et al. (1990).

The GLS closures are defined by the set of parameters $m$, $n, \sigma_{\kappa}, \sigma_{\Psi}, C_{\Psi 1}, C_{\Psi 2}$ and $C_{\Psi 3}$ but also $\alpha$ (Eq. 25) and $L$ (Eq. 26). We note that the parameter $p$ and then the factor $\left(C_{\mu}^{0}\right)^{p}$ appearing in the definition of $\Psi$ (Eq. 10) are mathematically irrelevant and introduced only to allow $\Psi$ to be completely identifiable with traditional quantities such as $\mathrm{kl}$, $\varepsilon$ and $\omega$. The constant $C_{\mu}^{0}$ is already set by the stability function inside the logarithmic boundary layer. Due to the standard turbulent flow test cases (e.g. mixed layer deepening, shear-free turbulence), Umlauf and Burchard (2003) explain the influence of each parameter, how to check its values and how to correct it if necessary. For example, the value of $C_{\Psi 3}$, under stable conditions, monitors the mixed layer deepening. Indeed, a Richardson number can be computed in a homogeneous stratified shear-flow in steady state. This number, called $R i_{\text {st }}$, depends on the stability functions (see Sect. 2.2.3) and on $C_{\Psi 3}$. The values of $C_{\Psi 3}$ shown in Table 1 were computed with $R i_{\mathrm{st}}=0.25$ using the Canuto A stability functions. The value of 0.25 was determined by comparison with the measurements of the Kato-Phillips experiment (further discussed below). Then, the value of $C_{\Psi 3}$ for the $k-k l$ model was adjusted to 2.62 by Burchard (2001a). This value is significantly higher than the initial value of 0.9 suggested by Mellor and Yamada (1982). Some values for the other stability functions can be found in Warner et al. (2004).

The well-known failure of $k-k l$ to respect the law of the wall required the addition of a wall function $F_{\text {WALL }}$ to the $C_{\Psi 2}$ constant. The wall function implemented in NEMO was initially suggested by Mellor and Yamada (1982).

Umlauf and Burchard (2003) also suggested an optimal calibration of the model using the polymorphic nature of the generic model. Thus, the parameters $m$ and $n$ are also considered as model parameters to be set. According to the observations in grid stirring experiments, $\alpha$ and $L$ are primarily set to optimal values. The equations established in shear-free turbulence imply that $n$ depends only on $m$, which leads to an infinite number of solutions. For each pair $m$ and $n$, the other parameters can be easily determined thanks to the other physical constraints. These models are called "generic models". For the purposes of this paper, only the "generic model" determined by $(\alpha=-2 ; L=0.2 ; m=1$ and $p=0$ for implementation facility) is considered.

The results obtained with the GLS closures $(k-k l, k-\varepsilon, k-\omega$ and the generic model) and TKE are presented in this paper.

\subsection{The NEMO 1-D framework}

\subsubsection{Equations system}

NEMO is based on the 3-D primitive equations (Eq. 1a-1c) but it offers the possibility of reducing the complexity of the system by limiting the domain to just one water column. This is the 1-D approach (NEMO1D).

The set of equations, after simplification of all horizontal gradients in the primitive equations, then reduces to:

$$
\begin{aligned}
\frac{\partial u_{i}}{\partial t} & =-\frac{\partial}{\partial z} v_{\mathrm{t}} \frac{\partial u_{i}}{\partial z}+f_{i} \\
\frac{\partial T}{\partial t} & =\frac{1}{\rho_{0} C_{p}} \frac{\partial I\left(F_{\mathrm{sol}}, z\right)}{\partial z}-\frac{\partial}{\partial z} K_{\mathrm{t}} \frac{\partial T}{\partial z} \\
\frac{\partial S}{\partial t} & =-\frac{\partial}{\partial z} K_{\mathrm{t}} \frac{\partial S}{\partial z}+E_{\mathrm{f}}-P_{\mathrm{f}}
\end{aligned}
$$

as $v_{\mathrm{mol}} \ll v_{t}$ and $K_{\mathrm{mol}} \gg K_{\mathrm{t}}$ on the vertical, the molecular diffusive terms are dismissed.

The C-grid (Arakawa and Lamb, 1977) is commonly used in NEMO. For purely numerical reasons, the A-grid is henceforth used by NEMO1D as the velocity components and the scalar values are calculated at the same point.

Due to the equation simplifications and the low computational cost, NEMO1D is an ideal tool for studying the vertical component of NEMO.

\subsubsection{Space and time discretization}

The choice of the vertical grid is crucial. A compromise should be found between the resolution needed for a good representation of the oceanic processes and the computational cost, linked to the number of cells and the CourantFriedrichs-Lewy CFL criteria (Courant et al., 1928) which induce the time-step constraint.

Currently, for 3-D realistic applications using NEMO, there are two classes of vertical grids:

- low-resolution vertical grids with the thickness of first levels between 6 and $10 \mathrm{~m}$. The grid with 31 cells (Fig. 1), used in the standard ORCA2 configuration of NEMO and specifically designed for climate applications (Dufresne et al., 2013), is a good example. This is the first grid selected for this study and will be referred to as L31.

- high-resolution grids that typically have a thickness of $1 \mathrm{~m}$ in the first levels. The grid with 75 vertical cells described in Fig. 1 and referred to as L75 represents the second class of vertical grids in our study. This grid is used in the global $1 / 4^{\circ}$ and in the regional $1 / 12^{\circ}$ Mercator Océan reanalyses (Ferry et al., 2010, 2011) but also in projects such as DRAKKAR (DRAKKAR Group, 2007) or decadal predictions in the GIEC framework (Voldoire et al., 2013). 


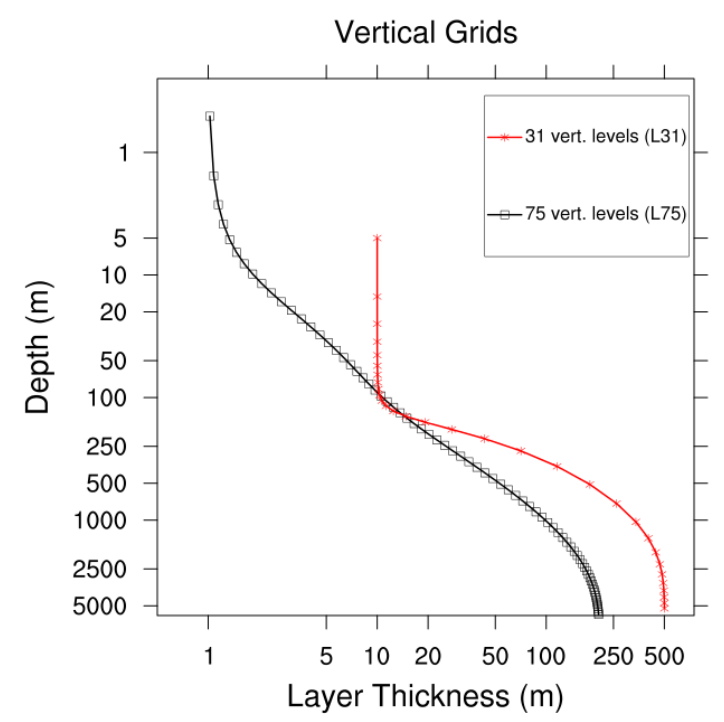

Figure 1. Thickness of vertical levels as a function of depth for two vertical grids: L31 (red) and L75 (black). Each plotting point (squares and stars) corresponds to the depth of levels.

The more interesting aspect, with respect to the test case results presented in the next sections, concerns the resolution of the first $10 \mathrm{~m}$ in which the MLD takes place. We note that L75 has more levels than L31 in the first $50 \mathrm{~m}: 18$ to 5. The layer thicknesses are of the order of $1 \mathrm{~m}$ in $\mathrm{L} 75$ but $10 \mathrm{~m}$ for L31.

Several time steps are used in 3-D simulations and these are fixed according to the spatial resolutions and their associated CFL conditions.

NEMO1D has no restriction on the time step, as there is no vertical advection and hence no CFL condition. However, we have tested the sensitivity of each turbulence model to the following time steps: 360, 1200 and 3600 s. These time steps correspond to those used in the global configurations at Mercator Océan and more generally in the research community. So we can easily regroup some pairs [vertical grid, time step] to retrieve some known configurations:

- [L75, $360 \mathrm{~s}]$ : Global configurations at $1 / 12^{\circ}$ (Deshayes et al., 2013; Treguier et al., 2014) used in Mercator Océan forecast system (Drévillon et al., 2008; Dombrowsky et al., 2009)

- [L75, 1200s]: Global configurations at $1 / 4^{\circ}$ used in global Mercator Océan reanalysis (Ferry et al., 2011) and DRAKKAR project (Barnier et al., 2006)

- [L31, 3600 s]: Global configurations at $1^{\circ}$ used for climatic studies (Hewitt et al., 2011)

- [L75, 3600s]: Global configurations at $1^{\circ}$ used for decadal forecast in the GIEC framework (Voldoire et al., 2013)
Special attention will be paid to these four pairs when we interpret the numerical results.

\subsubsection{Numerical implementation}

For the TKE model, $k$ is computed first by resolving Eq. (5). The mixing length $l$ is computed using Eq. (9) with bounding procedure. The turbulent coefficients are then deduced from Eq. (4a) and (4b) once the stability functions are computed.

For the GLS models, firstly, $\Psi$ and the dissipation rate $\varepsilon$ are reconstructed from the previous state of $k$ and $l$. Then the time evolution of $k$ (Eq. 5) and $\Psi$ (Eq. 11) but also the stability functions (Eq. 16a and 16b) are computed. $\varepsilon$ and $l$ are deduced from the new state of $\Psi$ (Eqs. 10 and 8). Finally, the turbulent coefficients are updated with Eq. (4a) and (4b).

To ensure a minimum level of mixing, background values are applied to the following turbulence quantities: $v_{\mathrm{t} 0}=1.2 \times 10^{-4} \mathrm{~m}^{2} \mathrm{~s}^{-1}, K_{\mathrm{t} 0}=1.2 \times 10^{-5} \mathrm{~m}^{2} \mathrm{~s}^{-1}, k_{0}=$ $10^{-6} \mathrm{~m}^{2} \mathrm{~s}^{-2}, \varepsilon_{0}=10^{-12} \mathrm{~m}^{2} \mathrm{~s}^{-3}$.

All the terms of the differential equations are solved explicitly except the diffusive terms appearing in Eqs. (5), (11) and (29a)-(29c), which are solved implicitly.

\section{Experimental design}

It is obvious that the TKE and GLS closures are very different from a purely physical aspect but also in the way they are implemented. If we were to perform a relevant comparison of these turbulence models, we should, for example, use the same boundary conditions or the same stability functions. The problem then should simply involve comparing a parameterization of the mixing length to that obtained with a differential equation.

But the aim of this paper is to provide feedback to NEMO users on the one- and two-equation turbulent closures available in the model.

\subsection{Idealized test case: the Kato-Phillips experiment}

\subsubsection{Description}

The Kato-Phillips (1969) experiment is classically used in the literature to test and calibrate turbulence models (e.g. Burchard, 2001a; Galperin et al., 1988). This laboratory experiment deals with the measurement of the mixed layer deepening of an initial, linear, stratified fluid, characterized by the Brunt-Väisälä frequency $N^{2}=10^{-4} \mathrm{~s}^{-2}$ and subjected to a constant surface friction represented by $u_{*}=$ $0.01 \mathrm{~m} \mathrm{~s}^{-1}$.

The model MLDs are then computed with criteria linked to the depth of the maximum of $N^{2}$ inside the water column and compared with those given by the empirical relation:

$\operatorname{MLD}(t)=\frac{1.05 u_{*} \sqrt{t}}{\sqrt{N(t=0)}}$. 


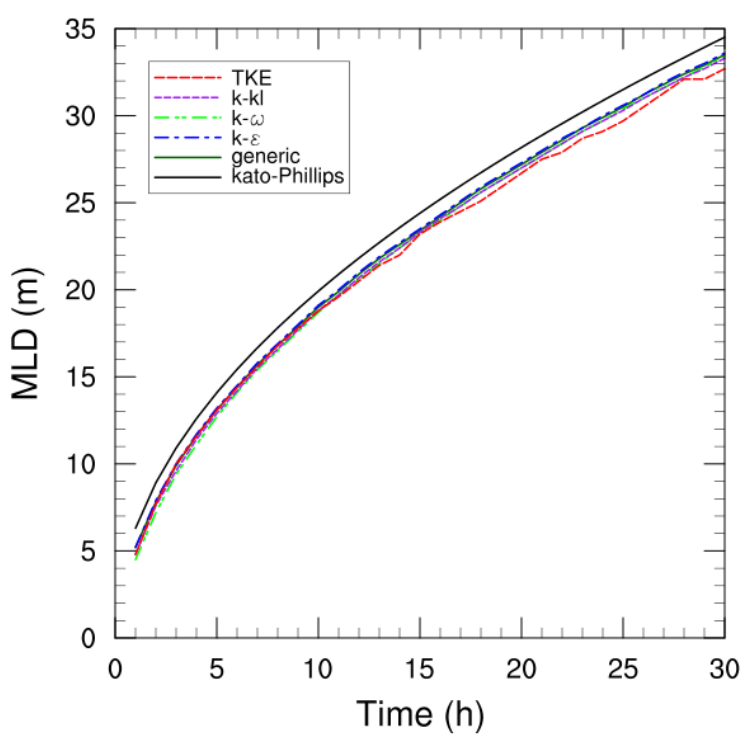

Figure 2. Time evolution of the MLD obtained as a function of the different turbulent closures with the 1000 levels vertical grid and a time step of $36 \mathrm{~s}$.

The MLDs calculated with Eq. (30) are reliable on timescales of the order of $30 \mathrm{~h}$, which determines the simulation duration.

To estimate the performance of each turbulence model, depending on the choice of the vertical grid and the time step, the metrics selected are the correlation coefficient, the standard deviation and the root mean square error (RMSE) of the simulated MLD compared to the analytic one given by Eq. (30).

The writing frequency for outputs is set by the highest time step considered in this study, i.e. 3600 s.

The surface boundary conditions are those described in Eqs. (18)-(20). Obviously we did not consider the wave breaking effect on the mixing. Nevertheless, the background value for the surface roughness was retained.

\subsubsection{Reference simulation}

As NEMO1D has a low computational cost, a new vertical grid was adopted and a water column of $100 \mathrm{~m}$ considered. This new vertical grid has 1000 levels (hereafter called L1000) at $10 \mathrm{~cm}$ intervals. Coupled with a time step of $36 \mathrm{~s}$, this numerical framework is ideal for checking the ability of all the turbulence models considered in this study to reproduce satisfactorily the empirical time-dependent relation (Eq. $30)$. Figure 2 shows that all the models gave very similar results close to the empirical solution. However, the numerical MLDs were slightly underestimated by approximately $1 \mathrm{~m}$ : the RMSEs were between $0.9 \mathrm{~m}$ for $k-\varepsilon$ and $1.4 \mathrm{~m}$ for TKE.

\subsubsection{Results}

In realistic 3-D global or regional configurations, the numerical framework is less favourable for obvious computing time or storage reasons. The vertical grids are then coarser (typically L31 or L75) with greater time steps. Nevertheless, these time steps are limited by the CFL condition, mainly on the vertical, and thus set by the choice of the grid. This numerical restriction does not occur in NEMO1D due to the noadvection assumption. Consequently, we have taken into account the 60 possibilities ( 5 turbulence models $\times 3$ vertical grids $\times 4$ time steps). As stated previously, we focused on the four pairs described at the end of Sect. 2. As expected, and as shown in Fig. 3, the deepening of the MLDs cannot be continuous in time but occurs in steps, determined by the vertical resolution. The number of levels near the surface is crucial to this process.

For the pair [L75, 360s] (Fig. 3a), all the models yielded suitable results with associated RMSEs of the order of $3 \mathrm{~m}$. For the pair [L75, 1200s] (Fig. 3b), all the models were close with RMSEs around $4 \mathrm{~m}$, except for $k-\omega$, which exhibited a high RMSE value of $10 \mathrm{~m}$. Concerning the pair [L75, 3600 s] (Fig. 3c), $k-\varepsilon$ and TKE exhibited the best results with an RMSE slightly greater than $7 \mathrm{~m}$. The three other models did not provide satisfying results in this numerical context. The RMSEs were higher: 10,13 and $15 \mathrm{~m}$ respectively for the generic, $k-k l$ and $k-\omega$.

The numerical context of the pair [L31, 3600 s] (Fig. 3d) is obviously the most difficult. The L31 vertical grid is not well adapted for this test case due to its coarse surface layer resolution with a $10 \mathrm{~m}$ separation of the first levels. The thresholds linked to the vertical grid are such that the RMSE should not be compared to those obtained with the L75 grid. It should be noted that (i) all closures represent the deepening of the maximum of $N^{2}$ (ii) all GLS closures show a quicker deepening of the MLD compared to the TKE solution. The MLD reaches $20 \mathrm{~m}$ during the first $10 \mathrm{~h}$ and there is no signal with TKE closure. This is due to the implementation of the surface boundary condition on two points in the GLS closures.

To represent synthetically the 60 possibilities of our test cases, the performed statistics (RMSE and correlation) were condensed in a Taylor diagram (Fig. 4). Note that the red and blue cloud points, corresponding to the tests done respectively with L1000 and L75 grids, are, for most of them, statistically close to the reference solution with a standard deviation lower than $25 \%$ and a correlation greater than $95 \%$. However, $k-\omega$ and $k-k l$ appear to be very sensitive to the chosen time step (numbers 3 and 4 in red and blue on the diagram) and have a normalized RMSE weaker than 0.75, even though the correlation is still good (greater than 0.95).

The green points, corresponding to tests using the L31 grid, show that all the turbulence models yielded very similar results at this resolution. The dispersion was only due to the normalized standard deviation while the RMSEs are sim- 

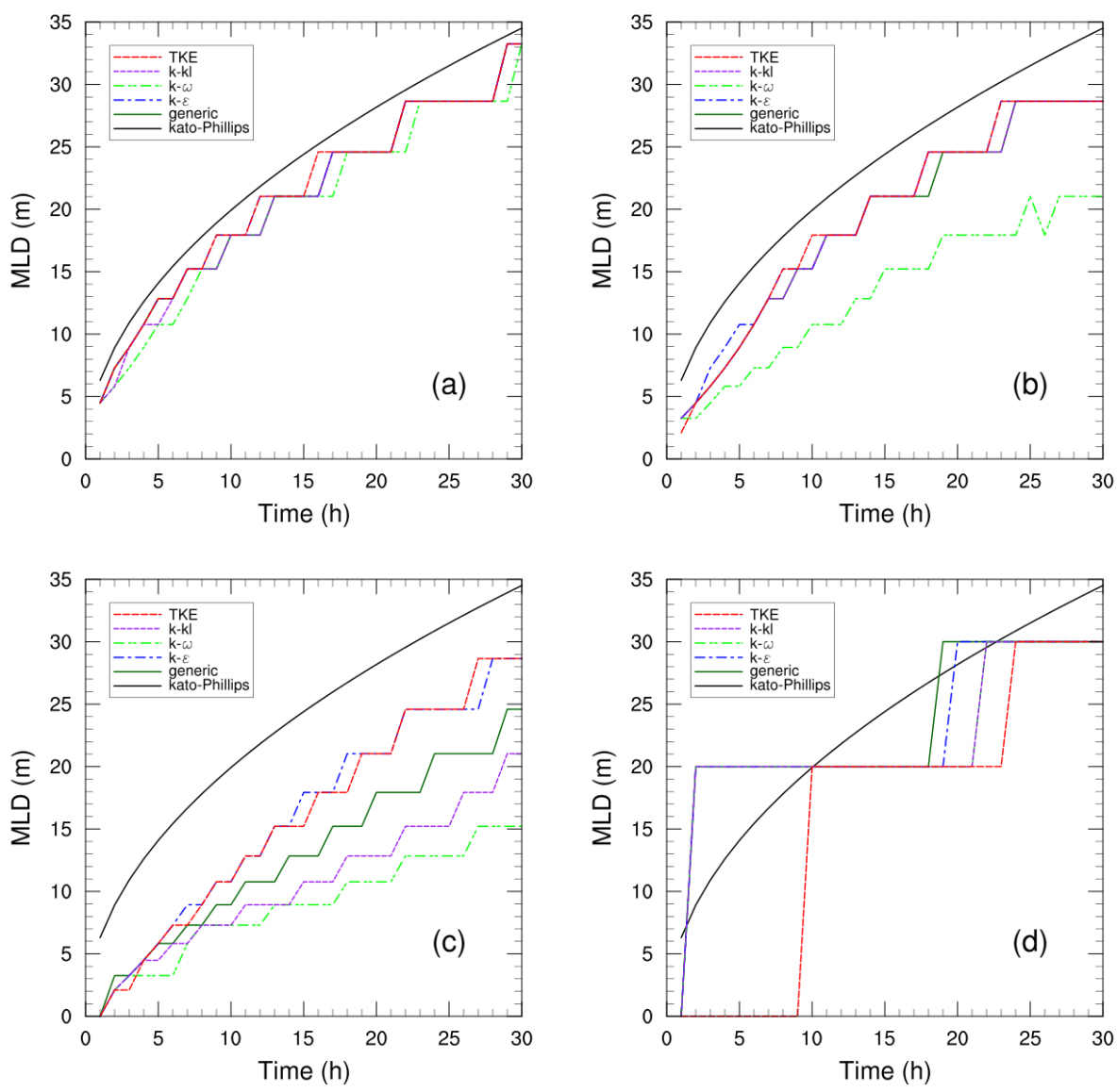

Figure 3. Time evolution of the MLD obtained with the different turbulence models for the pairs [L75, 360 s] (a), [L75, 1200 s] (b), [L75, $3600 \mathrm{~s}]$ (c), [L31, $3600 \mathrm{~s}]$ (d).

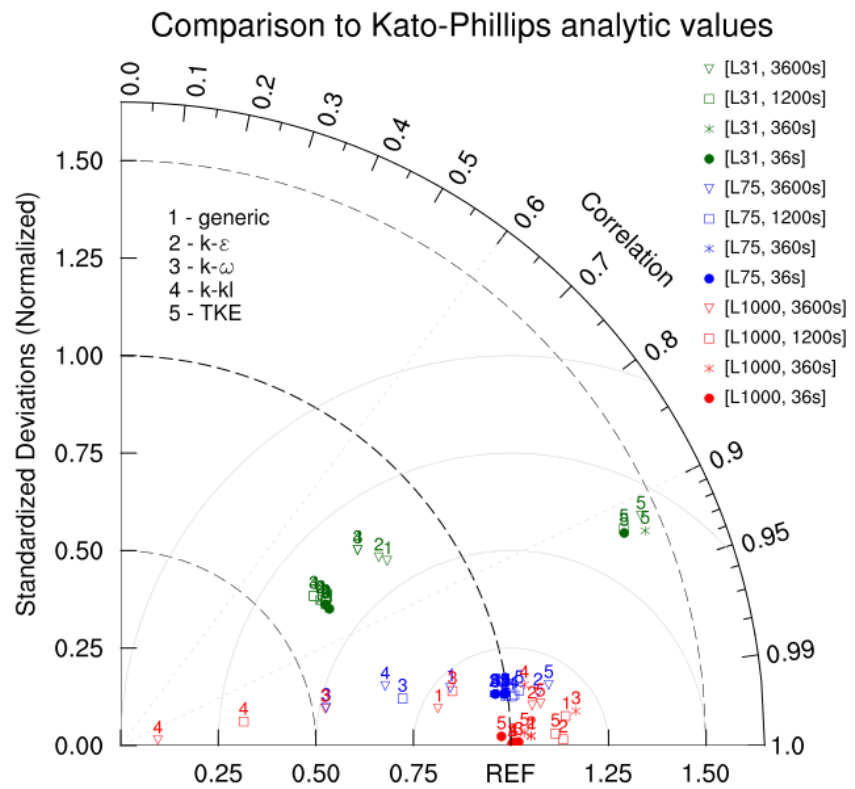

Figure 4. Taylor diagram of the 60 Kato-Phillips experiments. ilar. This kind of scatter is only influenced by the fact that the solution could be above or below the step of the coarse vertical discretization near the surface (Fig. 3d).

\subsection{PAPA station}

\subsubsection{Description}

The PAPA station, located west of Canada in the Pacific Ocean $\left(50^{\circ} \mathrm{N}, 145^{\circ} \mathrm{W}\right)$, has been intensively studied in the literature (Gaspar et al., 1990; Burchard, 2001a; Mellor and Durbin, 1975). The resulting measurements are particularly well adapted for a study following a 1-D approach, and for validating and calibrating any turbulence model. Indeed, there is no interaction with the coast and the horizontal advections of heat and salt are weak. High-quality measurements of ocean properties (temperature, salinity, velocities) and atmospheric conditions (wind, humidity, air temperature, heat fluxes and precipitation rate) are available for this site.

The temperature and salinity time series exhibits a wellmarked seasonal variability (Fig. 5). The temperature field shows the formation of stratification in summer followed by a homogenization of the water column in winter. The 
salinity field exhibits a stationary halocline at a depth of around $120 \mathrm{~m}$ while the surface variability is strongly correlated to the temperature field. Indeed, during strong stratification events, the MLD of only several tens of metres is isolated from the rest of the water column and when subjected to the precipitation rate, the salinity decreases. Next, during water column homogenization events, the salinity increases due to mixing with the deeper saltier waters. Note that the halocline depth can vary significantly during these several years of measurements (between 100 and $150 \mathrm{~m}$ in depth). This interannual variability is mostly attributed to variations in horizontal salt advection.

In this section, we compare all the turbulence model results with the data collected at the PAPA station between 15 June 2010 and 15 June 2011. For this period, there is no significant gap in the time series and the halocline depth remains stationary (120 m depth), i.e. advection is less influential.

\subsubsection{Numerical configuration}

\section{Input files}

A NEMO1D simulation is easily set up. The bathymetry considered is the value of the global bathymetry file at $1 / 4^{\circ}$ of resolution (Barnier et al., 2006) at the geographic point $\left(50^{\circ} \mathrm{N}, 145^{\circ} \mathrm{W}\right)$ and the depth is $4198 \mathrm{~m}$. The climatological chlorophyll values, required to calculate the light penetration, were also deduced from the global $1 / 4^{\circ}$ input file built from the monthly SeaWIFS climatological data (McClain et al., 2004). At the PAPA station location, these values remain weak and range between 0.27 and $0.43 \mathrm{mg} \mathrm{Chl} \mathrm{m}^{-3}$. The penetration light scheme used was based on the light decomposition following the red, green and blue wavelengths (Jerlov, 1968).

The $3 \mathrm{~h}$ atmospheric forcing came from the European Centre for Medium-Range Weather Forecasts (ECMWF) analysis and forecasting operational system. Although atmospheric measurements are taken at the PAPA station, they are only available once a day. However, these data are useful for checking that the ECMWF atmospheric fields are relevant enough to be used with confidence. Statistical comparisons (mean of the model minus observations, correlation coefficients and RMSEs) are shown in Table 2. Mean errors for wind velocities and air temperature are very small (respectively $1 \mathrm{~m} \mathrm{~s}^{-1}$ and $0.02{ }^{\circ} \mathrm{C}$ ) and the correlations are greater than 0.98 . The atmospheric model assimilates these data. The radiative fluxes are well correlated contrary to the precipitation rate with a correlation coefficient of only 0.76 . There is no marked seasonal cycle concerning the precipitation rate in observed data and ECMWF outputs (not shown in this paper). We conclude that the ocean summer stratification is primarily due to atmospheric heat fluxes. The relative humidity correlates well but shows a constant bias (RMSE value very close to the mean bias value) of almost $6 \%$. Globally, these
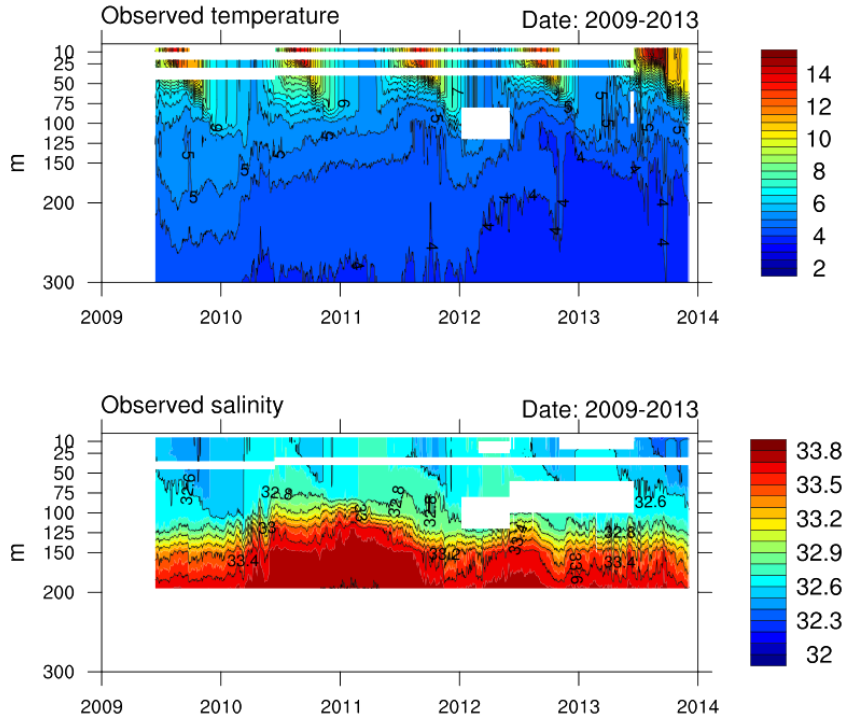

Figure 5. Temperature (top) and salinity (bottom) measured at the PAPA station covering the period 2009-2013.

statistics show that the atmospheric fields from the ECMWF system can be used for this study.

Regarding initial conditions, it would be ideal to initialize the model with temperature and salinity measurements taken at the PAPA station on 15 June 2010. However, the data cover only the first $200 \mathrm{~m}$ for salinity and the first $300 \mathrm{~m}$ for temperature. Moreover, the salinity and temperature data are not collected on the same vertical grid: 24 levels for the temperature as opposed to 18 levels for the salinity. Thus, below a depth of 200 or $300 \mathrm{~m}$, data from the WOD09 climatology (Levitus et al., 2013) were considered. Fortunately, there is a close match between the measurements and the climatology data below a depth of $150 \mathrm{~m}$ (Fig. 6).

\section{Model settings}

For simulations under realistic conditions, the turbulence models should take into consideration mixing caused by breaking waves. Thus, the surface boundary conditions are those described in Sect. 2.2.4 (Eqs. 24-26 for the GLS models and Eq. 22 for the TKE model). Moreover, the TKE model takes into account the injection of surface energy inside the water column as described in Eq. (23). This parameterization depends on the parameters $\alpha_{\mathrm{bc}}$ and $H_{\mathrm{p}}$. In order to estimate their impact on the MLD dynamics, three cases are considered, corresponding to the three cases available in NEMO for this latitude: $\alpha_{\mathrm{bc}}=0$ (no_penetration), $H_{\mathrm{p}}=10 \mathrm{~m}$ and $H_{\mathrm{p}}=30 \mathrm{~m}$. Thus, three distinct TKE models are defined: TKE_0m, TKE_10m and TKE_30m.

The bulk formulae used have been described in Large and Yeager (1994). The albedo coefficient is set to $6 \%$, the atmospheric pressure to $100800 \mathrm{~Pa}$ and the air density to 
Table 2. Comparisons of ECMWF atmospheric values and measurements at the PAPA station.

\begin{tabular}{lrrrrrrr}
\hline & $\mathrm{T} 2 \mathrm{~m}$ & Humidity & Wind $i$ & Wind $j$ & Solar flux & Non-solar flux & Rain \\
\hline $\begin{array}{l}\text { Mean bias (model } \\
\text { minus observations) }\end{array}$ & $0.02^{\circ} \mathrm{C}$ & $-6.13 \%$ & $0.54 \mathrm{~m} \mathrm{~s}^{-1}$ & $0.52 \mathrm{~m} \mathrm{~s}^{-1}$ & $10.3 \mathrm{~W} \mathrm{~m}^{-2}$ & $-11.64 \mathrm{~W} \mathrm{~m}^{-2}$ & $0.065 \mathrm{~m} \mathrm{~d}^{-1}$ \\
$\begin{array}{l}\text { Correlation } \\
\text { RMSE }\end{array}$ & 0.99 & 0.94 & 0.98 & 0.98 & 0.91 & 0.95 & 0.76 \\
& $0.33^{\circ} \mathrm{C}$ & $6.94 \%$ & $1.07 \mathrm{~m} \mathrm{~s}^{-1}$ & $1.26 \mathrm{~m} \mathrm{~s}^{-1}$ & $31.67 \mathrm{~W} \mathrm{~m}^{-2}$ & $16.5 \mathrm{~W} \mathrm{~m}^{-2}$ & $0.13 \mathrm{~m} \mathrm{~d}^{-1}$ \\
\hline
\end{tabular}
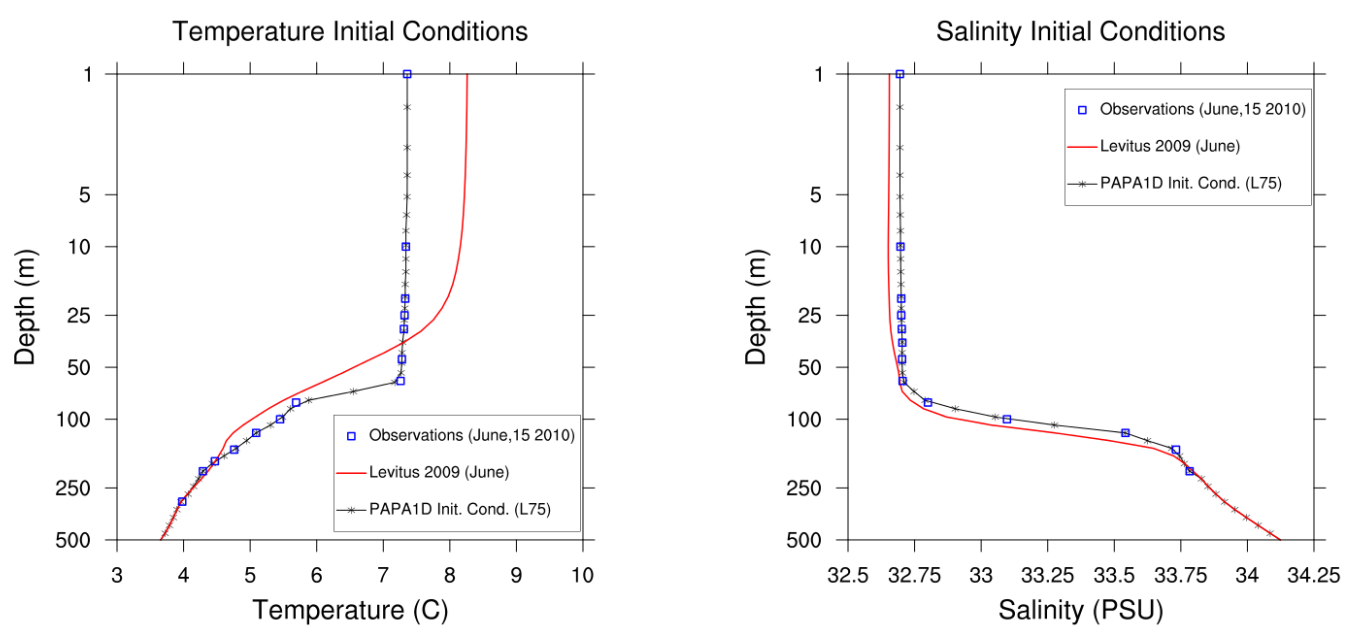

Figure 6. Initial conditions (black line and star) of temperature (left) and salinity (right) from measurements at the PAPA station (blue square) on 15 June 2010 and Levitus 2009 climatology data (red).

$1.22 \mathrm{~kg} \mathrm{~m}^{-3}$. For this study, the ocean surface velocities are not taken into consideration in the stress computation.

For these experiments, the two vertical grids (L31 and L75) and the three different time steps (360, 1200, 3600 s) described in Sect. 2 have been taken into account. All possible pairs with all closures (four issued from GLS formulation and three different TKEs) have been performed. This involved 42 simulations. The next section gives the results obtained with the pair with the highest resolution [L75, 360 s]. This pair is the selected setting for the standard configuration PAPA1D. The last section discusses the spatio-temporal sensitivity.

\subsubsection{Results with the pair $[\mathbf{L} 75,360 \mathrm{~s}]$}

Figures 7 and 8 represent the observed temperature and the observed salinity respectively at the PAPA station and the biases (model minus observation) obtained with different closures.

During the year of simulation, the summer stratification is well represented with an increase of temperature of $6^{\circ} \mathrm{C}$ at a depth of $10 \mathrm{~m}$ between the initialization (15 June) and the maximum at the beginning of September. The halocline is close to $100 \mathrm{~m}$ depth except between November and February, when it is located at $80 \mathrm{~m}$ depth. This depth variation is probably due to advective effects, which the model cannot reproduce. Above the MLD formed by the stratification, an increase of freshwater from August to November can be observed with a minimum of 32.4 PSU in October.

In all simulations, this annual cycle is found and the general behaviour is the same, except for the simulation TKE_30m in which the differences between simulated temperature and measurements exhibit, during summer, a vertical dipole, with a colder temperature than that observed, reaching $-2{ }^{\circ} \mathrm{C}$, in the first $40 \mathrm{~m}$ and warmer $\left(+2{ }^{\circ} \mathrm{C}\right)$ below $40 \mathrm{~m}$. This dipole is indicative of excessive mixing and the lack of stratification as shown on density profiles in Fig. 9. The vertical temperature gradient for the TKE_30m experiment (pink line) is smoother than the observed one (dark line). Consequently, a large amount of heat is introduced into the ocean and leads to a warming of $2{ }^{\circ} \mathrm{C}$ in the $40-120 \mathrm{~m}$ layer, especially during autumn and winter. As the thermocline is not present, the seasonal variability of the salinity cannot be investigated (Fig. 8). During winter (November to March), the excessive turbulent mixing partially destroys the halocline and the biases show the formation of a vertical dipole with water that is too salty $(+0.15$ PSU) in the upper $80 \mathrm{~m}$ and too fresh below, with respect to the observation data. Consequently, we can conclude that the mixing is too strong in the first $100 \mathrm{~m}$ in this experiment.

The biases obtained for the experiments with the other turbulence models ( $k-\varepsilon$, generic, $k-\omega, k-k l$, TKE_10m and TKE_0m) do not exhibit an excessive mixing as for the 

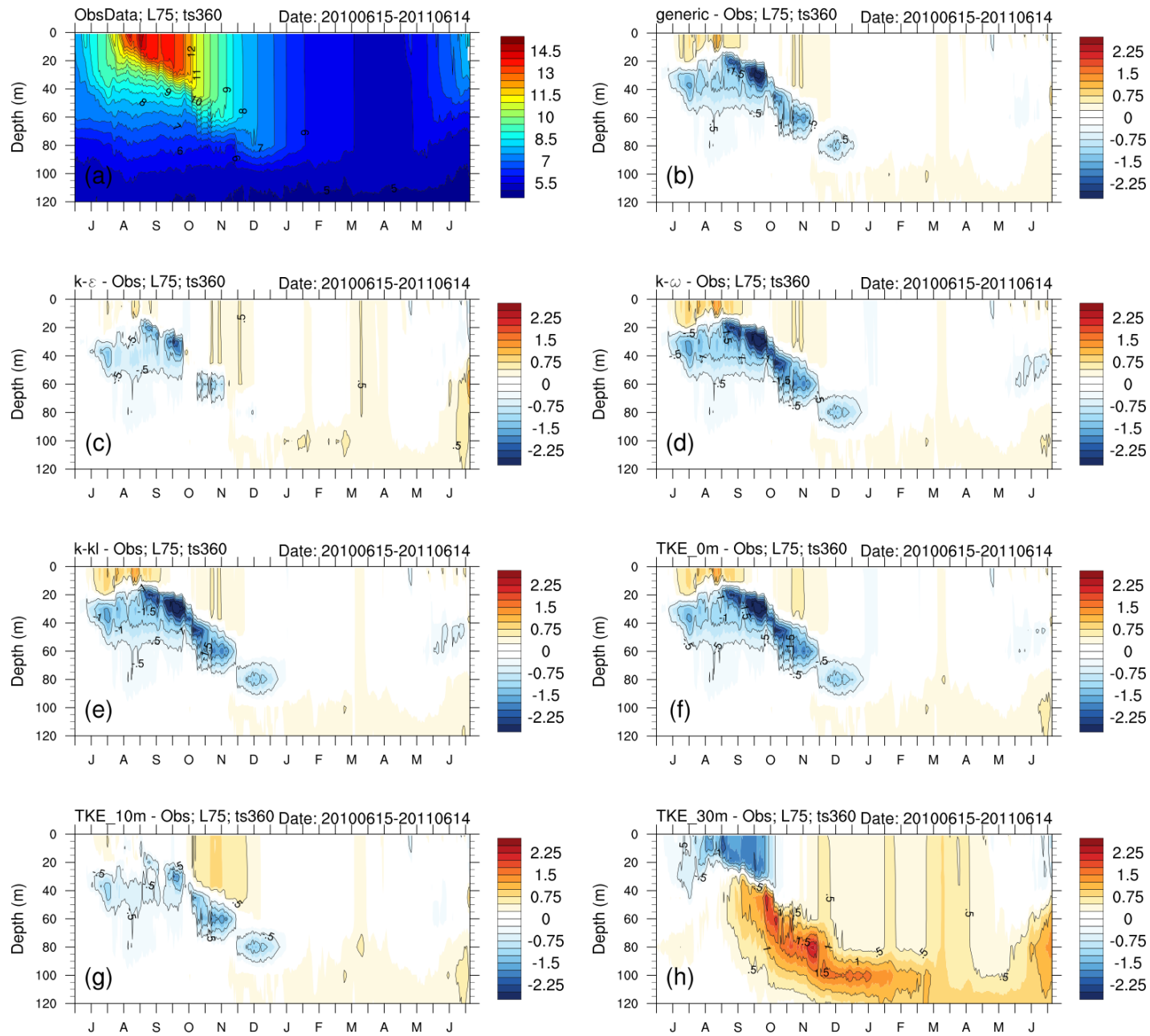

Figure 7. Observed temperature at PAPA station (a) over the study period (15 June 2010 to 14 June 2011) and the biases (model minus observed data) obtained in the simulations with all closures, with [L75; $360 \mathrm{~s}]$ : generic (b), $k-\varepsilon$ (c), $k-\omega(\mathbf{d}), k-k l$ (e), TKE_0m (f), TKE_10m (g) and TKE_30m (h). Iso-lines are plotted every $0.5^{\circ} \mathrm{C}$ (except for the iso-0, which has not been plotted).

TKE_30m experiment. On the contrary, the models tend to stratify too much during the summer as shown in Fig. 7, in which the temperatures of all these closures are too warm in the first $20 \mathrm{~m}\left(+1{ }^{\circ} \mathrm{C}\right.$ for generic, $k-\omega, k-k l$, TKE_0m and $+0.5^{\circ} \mathrm{C}$ for $k-\varepsilon$, TKE_10m) and too cold in the layer 20 $80 \mathrm{~m}\left(-2{ }^{\circ} \mathrm{C}\right.$ for generic, $k-\omega, k-k l$, TKE_0m and $-1{ }^{\circ} \mathrm{C}$ for $k-\varepsilon$, TKE_10m) with respect to the observation data.

As the precipitation rate has little influence on MLD dynamics (see Sect. 3.2.1), the salinity biases (Fig. 8) are directly linked to the MLD thickness by mixing and by evaporation. For the period from June to September, all the models exhibit the same weak salinity biases, as the MLD deepening is similar in each case. In October, for generic, $k-\omega, k-k l$, TKE_0m and TKE_10m closure, significant biases appear at a depth of $40 \mathrm{~m}(+0.1 \mathrm{PSU})$ and are trapped between $80 \mathrm{~m}$ and $100 \mathrm{~m}$ ( $>0.2 \mathrm{PSU}$ ) from December to the end of the simulation. Consequently, these trapped saltier waters modify the halocline structure and are not mixed with the surface water. This induces a freshwater bias ( -0.1 PSU) in the first $80 \mathrm{~m}$ during March to June. Such biases are not found in the results obtained with $k-\varepsilon$. The key process seems to occur in October when the atmospheric heat fluxes decrease and lead to the destruction of the stratification, thus generating a significant mixing. The density profiles of 12 October, plotted in Fig. 9, show that only $k-\varepsilon$ is able to correctly reproduce the MLD deepening. The underlying saltier waters are then correctly injected into the MLD. Due to that, $k-\varepsilon$ is the only closure that conserves the halocline intact and there is no fresh bias at the end of the simulation.

Regarding the sensitivity of the TKE model to the $H_{\mathrm{p}}$ parameter, $H_{\mathrm{p}}$ appears to be critical. The value of $30 \mathrm{~m}$ is too high, at least for the geographic location of the PAPA station, and does not reproduce summer stratification or conserve the deep halocline. On the other hand, in the case where no penetration is considered, the model tends to over-stratify and the MLD is not thick enough. As expected, an intermediate value 

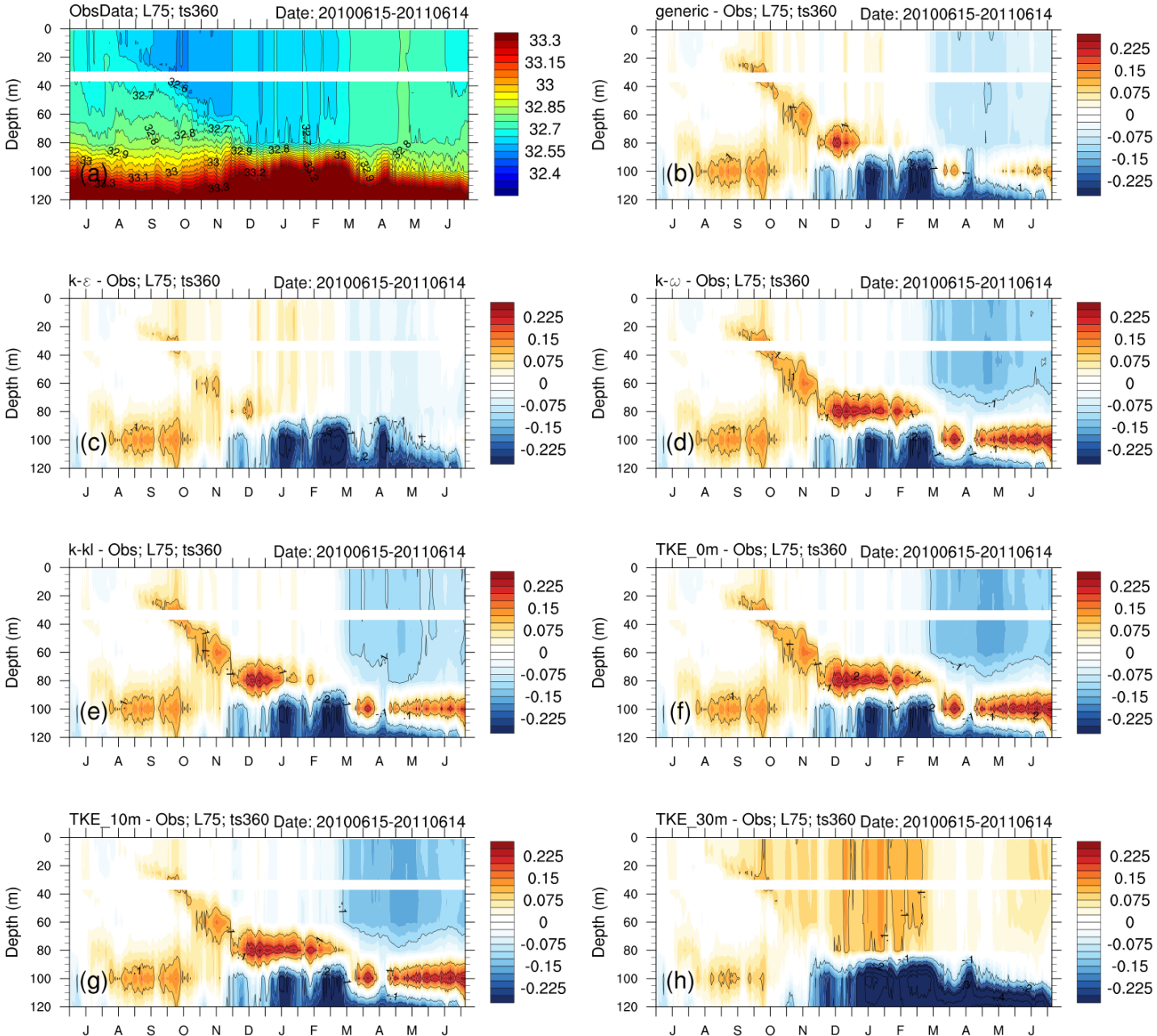

Figure 8. Observed salinity at PAPA station (a) over the study period (15 June 2010 to 14 June 2011) and the biases (model minus observed data) obtained in the simulations with all closures, with [L75; $360 \mathrm{~s}]$ : generic (b), $k-\varepsilon$ (c), $k-\omega(\mathbf{d}), k-k l$ (e), TKE_0m (f), TKE_10m (g) and TKE_30m (h). Iso-lines are plotted every 0.1 PSU (except the iso-0, which has not been plotted).

Density; VG75 ts360, Date: 2010-09-12

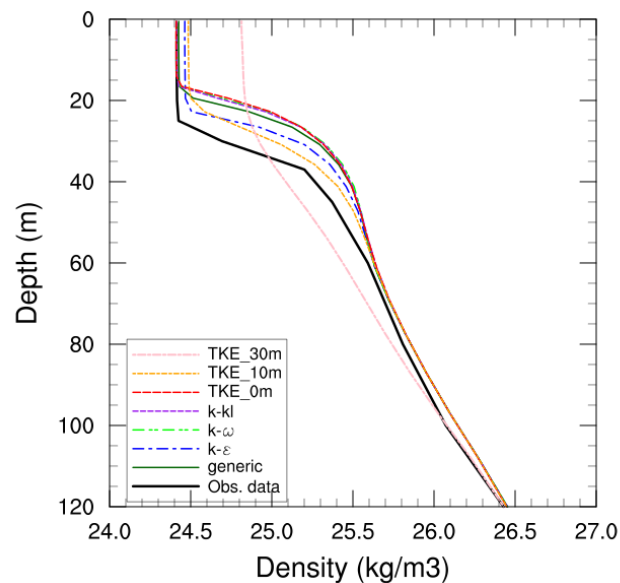

Density; VG75 ts360, Date: 2010-10-12

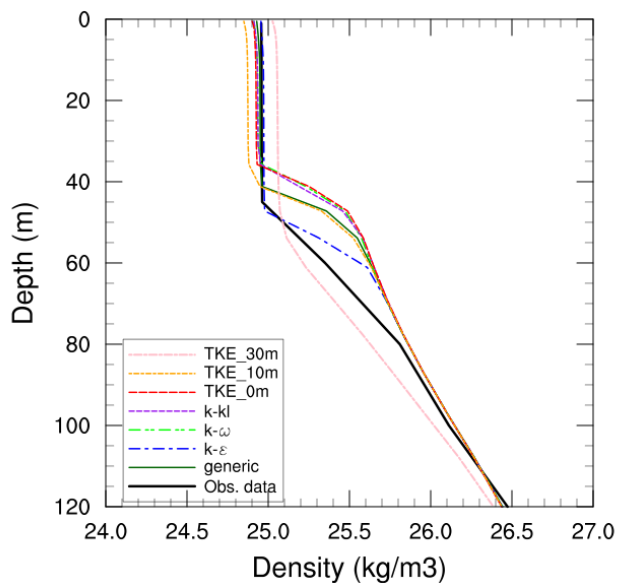

Figure 9. Daily vertical profiles of density during the stratified period (12 September 2010) on the left and at the beginning of the delayering period (12 October 2010) on the right. 

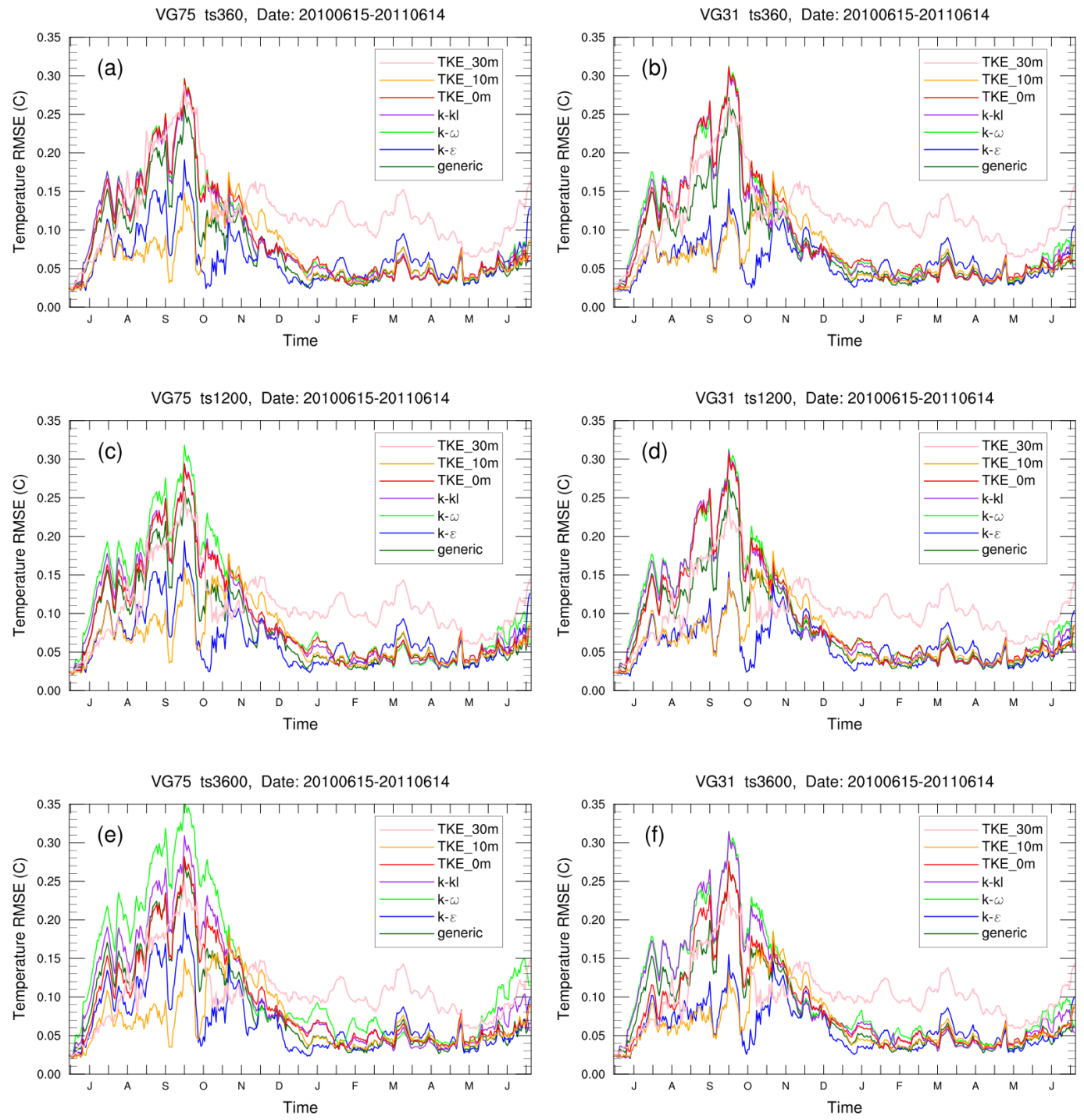

Figure 10. Evolution of the temperature RMSE computed along the vertical (0-120 m) for the pairs [L75, 360 s] (a), [L31, 360 s] (b), [L75, 1200 s] (c), [L31, $1200 \mathrm{~s}]$ (d), [L75, $3600 \mathrm{~s}]$ (e), [L31, $3600 \mathrm{~s}]$ (f) and different closures.

of $10 \mathrm{~m}$ provides more satisfying results but the setting of $H_{\mathrm{p}}$ can be more complex in the case of global ocean simulations.

\subsubsection{Spatiotemporal sensitivity}

As in Sect. 3.1.3, this section covers the sensitivity of the different closures to the vertical discretization (grid L75 and L31) and to the time step (360, 1200 and 3600 s). Figure 10 shows the evolution of the temperature RMSE for the different closures, computed for the first $120 \mathrm{~m}$ of the water column (depth corresponding to the halocline depth, Fig. 5).

In all cases, two periods can be distinguished: (i) from June to November 2010 corresponding to the stratified period, for which high variations of the RMSE have been observed (between 0.03 to $0.35^{\circ} \mathrm{C}$ ), (ii) from December 2010 to June 2011, corresponding to the period when no stratifi- cation takes place, for which the RMSE of all simulations is constant over the period (close to $0.12^{\circ} \mathrm{C}$ for TKE_30m and $0.05^{\circ} \mathrm{C}$ for other closures).

In both periods, the three TKE closures (red, orange and pink lines) do not show any significant sensitivity to the vertical discretization or the time step. This result is in agreement with the Kato-Phillips results presented in Sect. 3.1.

For the GLS closures, the two periods should be studied separately:

- During the first period (June to November 2010), the $k$ $\omega$ and $k-k l$ closures show a high sensitivity to the time step for a high-resolution grid (L75) as expected according to the Kato-Phillips results (Sect. 3.1.3). For example, with the $k-\omega$ closure and the $\mathrm{L} 75$ grid the maximum of RMSE is $0.28{ }^{\circ} \mathrm{C}$ with a time step of $360 \mathrm{~s}$ and in- 
VGL75 \& VGL31 ts3600, Date: 2010-08-20

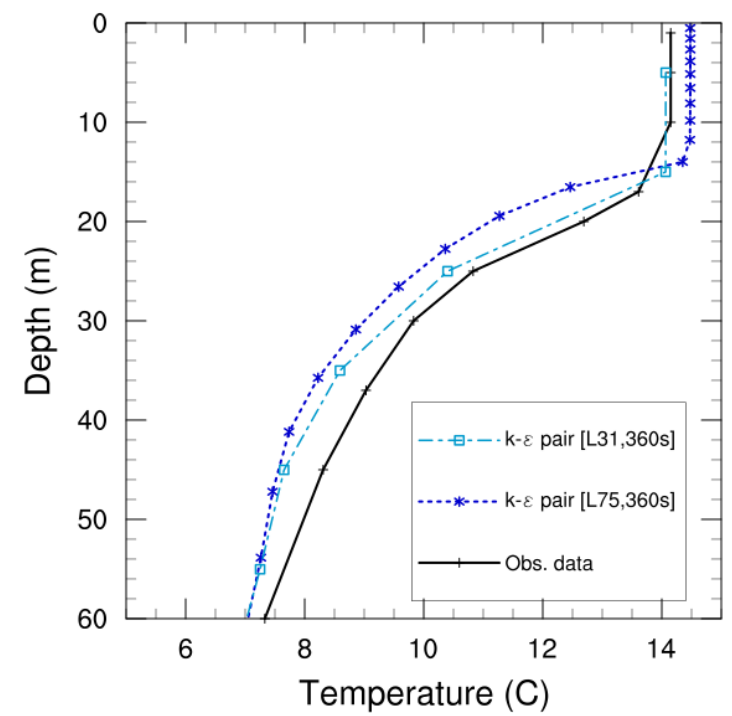

Figure 11. Daily vertical profiles of temperature for $20 \mathrm{Au}$ gust 2010: observed (black), simulated with $k-\varepsilon$ closure, a time step of $3600 \mathrm{~s}, \mathrm{~L} 31$ (light blue) and L75 (dark blue). The levels of observations and configurations are marked with squares (L31) or stars (L75).

creases to $0.35^{\circ} \mathrm{C}$ with a time step of $3600 \mathrm{~s}$ (green line in Fig. 10). The time-step variations have a weaker impact with L31 than with L75. The RMSE with $k-\omega$ stays close to $0.3^{\circ} \mathrm{C}$ in all $\mathrm{L} 31$ experiments. This result means that the time-step sensitivity is directly proportional to the vertical resolution. For a particular grid, the generic and $k-\varepsilon$ closures do not show a high sensitivity to the time step (dark and light blue in Fig. 10). The $k-\varepsilon$ closure gives the best results between these two closures, exhibiting an RMSE ranging between 0.03 and $0.2^{\circ} \mathrm{C}$. The generic RMSE varies from 0.05 to $0.25^{\circ} \mathrm{C}$.

- During the second period (December 2010 to June 2011), all the RMSEs are similar and weak $\left(0.05^{\circ} \mathrm{C}\right)$. The temporal variations over this period are small. Moreover, the closures have a small sensitivity to the vertical discretization and to the time step.

The RMSEs for $k-\varepsilon$ closure are better from August to September with L31 compared to those obtained with L75. For example, for 20 August and $360 \mathrm{~s}$, the RMSE of the simulation with $\mathrm{L} 75$ is $0.15^{\circ} \mathrm{C}$ and decreases to $0.08^{\circ} \mathrm{C}$ with L31 (blue line in Fig. 10).

To focus on this point, vertical temperature profiles for both vertical grids were plotted for this date (Fig. 11). L75 tends to over-stratify and this result is in agreement with the previous section (Fig. 7). The profile obtained with L31 agrees better with the observations (dark blue line). This is due to the numerical dilution effect of the coarse grid in the surface layer. Indeed, this grid has only three levels in the first
$30 \mathrm{~m}$ and is not able to create a strong stratification. In this case, a low vertical resolution becomes an advantage simply for numerical reasons.

\section{Conclusions and perspectives}

This paper has described the 1-D model version available in NEMO (NEMO1D). This model is very useful for isolating and studying vertical processes, and for improving their representation before switching to a 3-D model.

The present study focused on the behaviour of two types of turbulence closures available in NEMO, i.e. TKE and GLS. There are many differences between these two approaches, with respect to both the mixing length estimate and the constants used or boundary conditions. For this reason, we did not concentrate on comparing the closures but rather on their different strengths and weakness. Two test cases were selected, an "idealized" one, based on the experiment described in Kato-Phillips, and a "realistic" one, reproducing one year of salinity and temperature measured at the PAPA buoy.

The first test case was based on observations performed in a laboratory experiment. This experiment deals with the monitoring of the MLD deepening of an initially linear stratified fluid only subjected to a stationary surface stress. Because of its simplicity, this test case offers a perfect context for validating the numerical assumptions and implementations. Simulations were performed under favourable numerical conditions (grid with a resolution of $0.1 \mathrm{~m}$ and a time step of $36 \mathrm{~s}$ ). All the turbulence closures correctly reproduced the experimental results described even if the TKE closure slightly underestimates the MLD. This validates their implementation in NEMO. However, we found some dependence on numerical conditions (ratio time step/vertical discretization) for the GLS closures. This dependence is strong for $k$ $\omega$ and $k-k l$ and a little smaller for generic, $k-\varepsilon$ and the TKE closure.

The data collected at the PAPA station are typically used to perform studies with 1-D models. This mooring was naturally chosen to create a new reference configuration for NEMO. This new configuration was described, and then used to complement our study of TKE and GLS closures. The results show that these closures are largely able to reproduce the stratification/homogenization cycle observed at the station.

We have also demonstrated the major impact of a particular aspect of the boundary conditions on the TKE closure, via the parameter $H_{\mathrm{p}}$ that represents TKE penetration depth. Neglect of this TKE induces too strong a stratification and a value of $30 \mathrm{~m}$, which is too high, thus inducing too much mixing inside the water column. The best results at the PAPA station location are obtained with an intermediate value of $10 \mathrm{~m}$ but the optimal value of $H_{\mathrm{p}}$ could change as a function of the selected point in the world. The regionalization of this parameter highlights the difficulty of tuning the TKE model 
in a realistic 3-D simulation. GLS closures gave good results despite excessive summer stratification. Similar results to those of the Kato-Phillips experiment have been found for sensitivity to the numerical conditions (time step and vertical discretization): TKE closure does not show any sensitivity, generic and $k-\varepsilon$ are slightly sensitive and $k-\omega$ and $k-k l$ are very sensitive.

A key process has also been highlighted, namely the representation of salinity, occurring during the homogenization event in mid-October. All the models, except $k-\varepsilon$, underestimated the mixing and led to significant salinity biases in the vicinity of the halocline. These biases persisted throughout the entire simulation. Nevertheless, we found no signature for the temperature field. The $k-\varepsilon$ closure correctly simulates the homogenization phase. This is the only closure that conserves the halocline and exhibits the weaker salinity biases. By consequence, $k-\varepsilon$ is set as the standard turbulent model for PAPA1D even if TKE_10m gives very satisfactory results especially during the stratification phase. Currently, the TKE model is the standard model used by the NEMO community for 3-D model experiments. In light of the results presented in this paper, the standard value of $30 \mathrm{~m}$ for $\mathrm{H}_{p}$ seems too high at the PAPA station location. We think this parameter should be tuned with care or regionalized in the case of global simulations. 3-D sensitivity experiments should also be carried out with the $k-\varepsilon$, and interactions with the other vertical physical components should also be studied (solar penetration, bulk formulae, etc.).

The results obtained with NEMO1D were successfully compared with laboratory observations or in-situ measurements through a turbulent closure sensitivity study. The 1D approach, applied at the PAPA station (new NEMO reference configuration PAPA1D) or at another location, could be useful for further investigation of the turbulent mixing or some other physical component affecting vertical processes. Indeed, the MLD is subject to complex interactions between the turbulence, the surface forcing (including atmospheric fluxes and waves) and the boundary treatments.

Some of the following questions could be investigated using this numerical tool.

What is the behaviour of the other turbulence models of NEMO (KPP) (Large et al., 1994) and Paconowski and Philander (1981)? What is a more optimal value of some parameters $\left(H_{\mathrm{p}}\right.$, surface roughness, background values, etc.)? What is the sensitivity of the stability function? What would be the impact of another atmospheric data set (observed data or coming from another meteorological centre) or the forcing frequency ( 1 day, 3 hours, 1 hour, etc.)? What would be the impact of another forcing function (bulk formulae, flux form or atmospheric boundary layer model)? What would be the wave impact characterized for example through the Stokes drift or the Langmuir cells? What would be the impact of the solar flux penetration scheme that could incorporate two aspects: the chlorophyll fields used (temporal variability, observed at the surface or 3-D simulated field) or the penetra- tion radiation schemes (red-green-blue scheme such as the one used in this paper or a two-band scheme depending only on an attenuation depth)?

Finally, this 1-D model could also be useful for studies on coupling with atmospheric, ice or biogeochemical models.

Acknowledgements. This research was supported by the MyOcean2 European project and Mercator Océan. The authors wish to thank collaborators who have contributed to development of the NEMO ocean code as part of the NEMO consortium. We thank Yann Drillet, Jean-Michel Lellouche and Marie Drévillon for their useful comments and both reviewers for their very constructive suggestions and questions.

Edited by: R. Marsh

\section{References}

Arakawa, A. and Lamb, V. R.: Computational design of the basic dynamical processes of the UCLA general circulation model, Meth. Comp. Phys, New York: Academic Press, 17, 173-265, 1977.

Barnier, B., Madec, G., Penduff, T., Molines, J.-M., Treguier, A.M., le Sommer, J., Beckmann, A., Biastoch, A., Böning, C., Dengg, J., Derval, C., Durand, E., Gulev, S., Remy, E., Talandier, C., Theetten, S., Maltrud, M., Mc Clean, J., and de Cuevas, B.: Impact of partial steps and momentum advection schemes in a global circulation model at eddy permitting resolution, Ocean Dynam., 56, 543-567, doi:10.1007/s10236-006-0082-1, 2006.

Bernie, D. J., Guilyardi, E., Madec, G., Slingo, J. M., and Woolnough, S. J.: Impact of resolving the diurnal cycle in an oceanatmosphere GCM. Part 1: a diurnally forced OGCM, Clim. Dynam., 29, 575-590, doi:10.1007/s00382-007-0249-6, 2007.

Blanke, B. and Delecluse, P.: Variability of the Tropical Atlantic Ocean Simulated by a General Circulation Model with Two Different Mixed-Layer Physics, J. Phys. Ocean., 23, 1363-1388, 1993.

Burchard, H.: On the q21 equation by Mellor and Yamada (1982), J. Phys. Oceanogr., 31, 1377-1387, 2001a.

Burchard, H.: Simulating the Wave-Enhanced Layer under Breaking Surface Waves with Two-Equation Turbulence Models, J. Phys. Oceanog., 31, 3133-3145, 2001 b.

Burchard, H. and Bolding K.: Comparative Analysis of Four Second-Moment Turbulence Closure Models for the Oceanic Mixed Layer, J. Phys. Oceanogr., 31, 1943-1967, 2001.

Burchard, H. and Umlauf, L.: A Generic Length-Scale Equation for Geophysical Turbulence Models, J. Marine Res., 61, 235-265, 2003.

Burchard, H., Craig, P. D., Gemmrich, J. R., van Haren, H., Mathieu, P. P., Meier, H. E., Smith W., Prandke, H., Rippeth, T. P., Skyllingstad, E. D., Smyth, W. D., Welsh, D., and Wijesekera, H. W.: Observational and numeric al modeling methods for quantifying coastal ocean turbulence and mixing, Prog. Oceanogr., 76, 399-442, 2008.

Canuto, V. M., Howard, A., Cheng, Y., and Dubovikov, M. S.: Ocean turbulence. Part I: One-point closure model-momentum 
and heat vertical diffusivities, J. Phys. Oceanogr., 31, 1413-1426, 2001.

Chanut, J., Barnier, J., Large, W., Debreu, L., Penduff, T., Molines, J. M., and Mathiot, P.: Mesoscale eddies in the Labrador Sea and their contribution to convection and re-stratification, J. Phys. Oceanogr., 38, 1617-1643, 2008.

Charnock, H.: Wind stress on a water surface, Q. J. Roy. Meteor. Soc., 1, 639-640, 1955.

Courant, R., Friedrichs, K., and Lewy, H.: On the partial difference equations of mathematical physics, IBM J. Res. Dev., 11, 215234, 1928

Craig, P. D. and Banner, M. L.: Modeling wave-enhanced turbulence in the ocean surface layer, J. Phys. Oceanogr., 24, 25462559, 1994.

Deshayes, J., Treguier, A., Barnier, B., Lecointre, A., Sommer, J. L., Molines, J.-M., Penduff, T., Bourdalle-Badie, R., Drillet, Y., Garric, G., Benshila, R., Madec, G., Biastoch, A., Boning, C., Scheinert, M., Coward, A. C., and Hirschi, J.: Oceanic hindcast simulations at high resolution suggest that the Atlantic MOC is bistable, Geophys. Res. Lett., 40, 3069-3073, 2013.

Dombrowsky, E., Bertino, L., Bassington, G. B., Chassignet, E. P., Davidson, F., Hurlburt, H. E., Kamachi, M., Lee, T., Martin, M. J., Mei, S., and Tonani, M.: GODAE Systems in Operation, Oceanography, 22, 80-95, 2009.

DRAKKAR Group: Eddy-permitting ocean circulation hindcasts of past decades, CLIVAR Exchanges, 12, 8-10, 2007.

Drévillon, M., Bourdallé-Badie, R., Derval, C., Drillet, Y., Lellouche, J.-M., Rémy, E., Tranchant, B., Benkiran, M., Greiner, E., Guinehut, S., Verbrugge, N., Garric, G., Testut, C.-E., Laborie, M., Nouel, L., Bahurel, P., Bricaud, C., Crosnier, L., Dombrowsky, E., Durand, E., Ferry, N., Hernandez, F., Le Galloudec, O., Messal, F., and Parent, L.: The GODAE/MercatorOcean global ocean forecasting system: results, applications and prospects, J. Oper. Oceanog., 1, 51-57, 2008.

Dufresne, J. L., Foujols, M. A., Denvil, S., Caubel, A., Marti, O., Aumont, O., Balkanski, Y., Bekki, S., Bellenger, H., Benshila, R., Bony, S., Bopp, L., Braconnot, P., Brockmann, P., Cadule, P., Cheruy, F., Codron, F., Cozic, A., Cugnet, D., de Noblet, N., Duvel, J. P., Ethé, C., Fairhead, L., Fichefet, T., Flavoni, S., Friedlingstein, P., Grandpeix, J. Y., Guez, L., Guilyardi, E., Hauglustaine, D., Hourdin, F., Idelkadi, A., Ghattas, J., Joussaume, S., Kageyama, M., Krinner, G., Labetoulle, S., Lahellec, A., Lefebvre, M. P., Lefevre, F., Levy, C., Li, Z. X., Lloyd, J., Lott, F., Madec, G., Mancip, M., Marchand, M., Masson, S., Meurdesoif, Y., Mignot, J., Musat, I., Parouty, S., Polcher, J., Rio, C., Schulz, M., Swingedouw, D., Szopa, S., Talandier, C., Terray, P., Viovy, N., and Vuichard, N.: Climate change projections using the IPSL-CM5 Earth System Model: from CMIP3 to CMIP5, Clim. Dynam., 40, 2123-2165, 2013.

Ferry, N., Parent, L., Garric, G., Barnier, B., Jourdain, N. C., and the Mercator Ocean team: Mercator Global Eddy Permitting Ocean Reanalysis GLORYS1V1: Description and Results, Mercator Ocean Quarterly Newsletter, 36, 15-28, 2010.

Ferry, N., Parent, L., Masina, S., Storto, A., Haines, K., Valdivieso, M., Barnier, B., and Molines, J.-M.: QUality Information Document MyOcean V2 System For Global Ocean Reanalysis Product GLOBAL-REANALYSIS-PHYS-001-004-a and b, MyOcean document ref: MYO-WP04-QUID-V2-GLOREA-PHYS-001-004, 2011.
Flierl, G. and Davis C.: Biological effects of Gulf Stream meandering, J. Marine Res., 51, 529-560, 1993.

Galperin B., Kantha, H., Hassid, S., and Rosati, A.: A QuasiEquilibrium Turbulent Energy Model for geophysical flows, J. Atmos. Sci., 45, 55-62, 1988.

Gaspar, P., Grégoris, Y., and Lefevre, J. M.: A Simple Kinetic Energy Model for Simulations of the Oceanic Vertical Mixing: Tests at Station Papa and Long-Term Upper Ocean Study Site, J. Geophys. Res., 95, 16179-16193, 1990.

Hewitt, H. T., Copsey, D., Culverwell, I. D., Harris, C. M., Hill, R. S. R., Keen, A. B., McLaren, A. J., and Hunke, E. C.: Design and implementation of the infrastructure of HadGEM3: the nextgeneration Met Office climate modelling system, Geosci. Model Dev., 4, 223-253, doi:10.5194/gmd-4-223-2011, 2011.

Hossain, M. S.: Mathematische Modellierung von turbulenten Auftriebsstromungen, Ph.D. Dissertation, University of Karlsruhe, Germany, 145 pp., 1980.

Jerlov, N. G.: Optical Oceanography, Elsevier, 194 pp., 1968.

Kantha, L. H. and Clayson, C. A.: An improved mixed layer model for geophysical applications, J. Geophys. Res., 99, 2523525266, 1994.

Kato, H. and Phillips, O. M.: On the penetration of a turbulent layer into stratified fluid, J. Fluid Mech., 37, 643-655, 1969.

Large, W. G. and Yeager, S. G.: Diurnal to Decadal Global Forcing for ocean and Sea-Ice Models: The data sets and flux climatologies, NCAR Technical Note, 1994.

Large, W. G., McWilliams, J. C., and Doney, S. C.: Oceanic vertical mixing: a review and a model with a non-local boundary layer parameterization, Rev. Geophys., 32, 363-403, 1994.

Levitus, S., Antonov, J. I., Baranova, O. K., Boyer, T. P., Coleman, C. L., Garcia, H. E., Grodsky, A. I., Johnson, D. R., Locarnini, R. A., Mishonov, A. V., Reagan, J. R., Sazama, C. L., Seidov, D., Smolyar, I., Yarosh, E. S., and Zweng, M. M.: The World Ocean Database, Data Science Journal, 12, 229-234, Special Issue of the Proceedings of the 1st WDS Conference 20 in Kyoto, 3-6 September 2011, Kyoto University, Kyoto, Japan, 2013.

Madec, G.: NEMO Reference Manual, Ocean Dynamics Component: NEMO-OPA, Note du Pôle de Modélisation, 27, Institut Pierre-Simon Laplace (IPSL), France, 2008.

McClain, C. R., Feldman, G. C., and Hooker, S. B.: An overview of the SeaWiFS project andstrategies for producing a climate research quality global ocean bio-optical time series, Deep-Sea Res. Pt. II, 51, 5-42, 2004.

Mellor, G. and Blumberg, A.: Wave breaking and ocean surface layer thermal response, J. Phys. Oceanogr., 34, 693-698, 2004.

Mellor, G. and Durbin, P. A.: The structure and dynamics of the ocean surface mixed layer, J. Phys. Oceanogr., 5, 718-728, 1975.

Mellor, G. and Yamada, T.: Development of a Turbulence Closure Model for Geophysical Fluid Problems, Geophys. Space Phys., 20, 851-855, 1982.

Munk, W. H. and Anderson, E. R.: Notes on the theory of the thermocline, J. Marine Res., 3, 276-295, 1948.

Pacanowski, R. C. and Philander, S. G. H.: Parametrization of Vertical Mixing in Numerical Models of Tropical Oceans, J. Phys. Oceanogr., 11, 1443-1451, 1981.

Rascle, N., Ardhuin, F., Queffeulou, P., and Croizé-Fillon, D.: A global wave parameter database for geophysical applications, Part 1: Wave-current-turbulence interaction parameters for 
the open ocean based on traditional parameterizations, Ocean Model., 25, 154-171, doi:10.1016/j.ocemod.2008.07.006, 2008.

Rodi, W.: Examples of calculation methods for flow and mixing in stratified fluids, J. Geophys. Res., 92, 5305-5328, 1987.

Stacey, M. W.: Simulations of the wind-forced near-surface circulation in Knight Inlet: A parameterization of the roughness length, J. Phys. Oceanogr., 29, 1363-1367, 1999.

Townsend, A. A.: The Structure of Turbulent Shear flow, Cambridge University Press, 1976.

Treguier, A. M., Deshayes, J., Le Sommer, J., Lique, C., Madec, G., Penduff, T., Molines, J.-M., Barnier, B., Bourdalle-Badie, R., and Talandier, C.: Meridional transport of salt in the global ocean from an eddy-resolving model, Ocean Sci., 10, 243-255, doi:10.5194/os-10-243-2014, 2014.

Umlauf, L. and Burchard, H.: A generic length-scale equation for geophysical turbulence models, J. Marine Res., 61, 235-265, 2003.
Voldoire, A., Sanchez-Gomez, E., Salas y Mélia, D., Decharme, B., Cassou, C., Sénési, S., Valcke, S., Beau, I., Alias, A., Chevallier, M., Déqué, M., Deshayes, J., Douville, H., Fernandez, E., Madec, G., Maisonnave, E., Moine, M. P., Planton, S., SaintMartin, D., Szopa, S., Tyteca, S., Alkama, R., Belamari, S., Braun, A., Coquart, L., and Chauvin, F.: The CNRM-CM5.1 global climate model: description and basic evaluation, Clim. Dynam., 40, 2091-2121, doi:10.1007/s00382-011-1259-y, 2013.

Warner, J. C., Sherwood, C. R., Arango, H. G., and Signell, R. P.: Performance of four turbulence closure models implemented using a generic length scale, Meth, Ocean Model., 8, 81-113, 2004.

Wilcox, D. C.: Reassessment of the scale-determining equation for advanced turbulence models, AIAA Journal, 26, 1299-1310, 1988.

Xing, J. and Davies, A. M.: The effect of wind direction and mixing upon the spreading of a buoyant plume in a non-tidal regime, Cont. Shelf Res., 19, 1437-1483, 1999. 